\title{
WPS3446
}

\section{The Long-Term Legacy \\ of the Khmer Rouge Period in Cambodia}

\author{
Damien de Walque
}

ddewalque@worldbank.org

\section{Development Research Group}

The World Bank

\begin{abstract}
World Bank Policy Research Working Paper 3446, November 2004
The Policy Research Working Paper Series disseminates the findings of work in progress to encourage the exchange of ideas about development issues. An objective of the series is to get the findings out quickly, even if the presentations are less than fully polished. The papers carry the names of the authors and should be cited accordingly. The findings, interpretations, and conclusions expressed in this paper are entirely those of the authors. They do not necessarily represent the view of the World Bank, its Executive Directors, or the countries they represent. Policy Research Working Papers are available online at http://econ.worldbank.org.
\end{abstract}

I thank Tim Conway, Monica Das Gupta, Deon Filmer, John Gibson, Patrick Heuveline, Jennifer Hunt, Biju Rao, Ritva Reinikka, Norbert Schady, Filip Verwimp, seminar participants at the World Bank and conference participants at the NEUDC 2004 in Montreal for useful comments and discussions. 


\begin{abstract}
This paper studies the long-term impact of genocide during the period of the Khmer Rouge (1975-79) in Cambodia and contributes to the literature on the economic analysis of conflict. Using mortality data for siblings from the Cambodia Demographic and Health Survey in 2000, it shows that excess mortality was extremely high and heavily concentrated during 1974-80. Adult males have been the most likely to die, indicating that violent death played a major role. Individuals with an urban or educated background were more likely to die. Infant mortality was also at very high levels during the period and disability rates from landmines or other weapons are high for males who, given their birth cohort, were exposed to this risk.

The very high and selective mortality had a major impact on the population structure of Cambodia. Fertility and marriage rates were very low under the Khmer Rouge but rebounded immediately after the regime's collapse. Because of the shortage of eligible males, the age and education differences between partners tended to decline. The period had a lasting impact on the educational attainment of the population. The education system collapsed during the period, so individuals - especially males - who were of schooling age during this interval have a lower educational attainment than the preceding and subsequent birth cohorts.
\end{abstract}

\title{
Contents
}

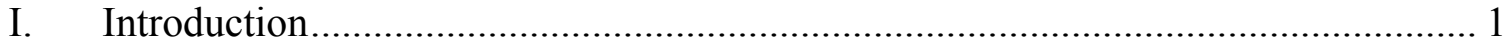

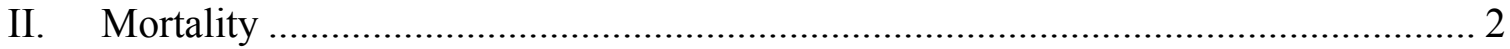

II.1 Extent and timing of excess mortality ........................................................ 4

II. 2 Violent mortality: mortality by birth cohort and gender................................. 5

II.3 Selective mortality: mortality by socio-economic status .............................. 6

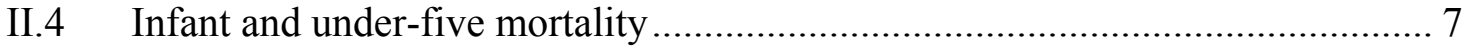

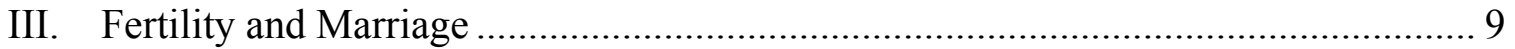

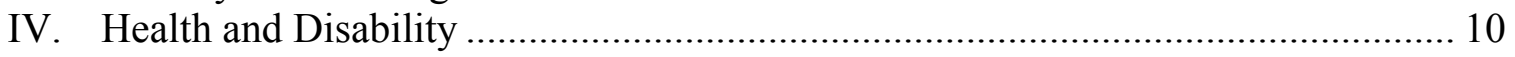

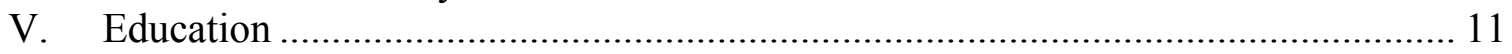

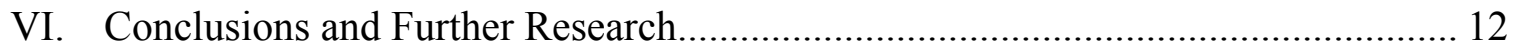

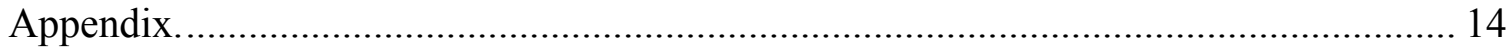

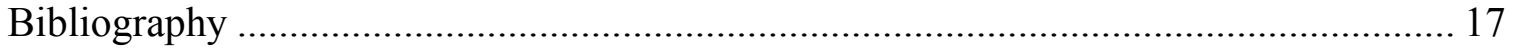




\section{Introduction}

Between 1975 and 1978, under the regime of the Khmer Rouge, Cambodia experienced a dramatic political shock: massive killings and starvation, large-scale population transfers, forced labor on collective farms, and an almost complete destruction of the school system.

The extreme atrocities endured by the Cambodians have been documented and identified as a genocide (Banister and Paige Johnson 1993; Chandler 1996; Kiernan and Boua 1982; Kiernan 1993; Kiernan 1996; Kiljunen 1984; Sliwinski 1995; Vickery 1984), however, few studies have quantified the extent or measured the long-term impact of these events. Using diverse micro-level representative surveys of Cambodia (Cambodia Socio-Economic Survey 1997, Demographic and Health Survey 2000, Labor Force Survey 2001), this paper investigates the long-term consequences of the Khmer Rouge period on a range of outcomes in today's Cambodia.

The aim of the analysis is to determine the legacy of the Khmer Rouge period on the current population structure, health status, and schooling levels in Cambodia. The excess mortality of the 1970s dramatically affected the population composition. Using data from siblings' mortality in the Cambodia Demographic and Health Survey, I show that excess mortality was heavily concentrated in the $1974-80$ period. I also show that adult males were most likely to die, indicating that violent deaths represented a large share of the excess mortality. Individuals with an urban or educated background were more likely to die, establishing that they were especially targeted. Infant and under-five mortality was also at very high levels around the Khmer Rouge period. For cohorts exposed to the risk of violence during the period, disability rates are much larger for males than for females and this is mainly due to disability caused by landmines and other weapons.

Fertility and marriage rates were very low under the Khmer Rouge but rebounded dramatically immediately after. Since the death toll was extremely heavy for adult males, the marriage market seems to have adapted by reducing the age difference between partners.

As the school system was ruined under the Khmer Rouge regime, one of the lasting legacies of the period is also that individuals, and in particular males, who were of schooling age at the end of the 1970s have a lower level of educational achievement than the preceding and subsequent birth cohorts. 
The paper contributes to the literature on the economic analysis of conflict. Most of this literature focuses on the causes of conflicts or analyzes their economic consequences in a macro or cross-country framework (Collier and others 2003, Collier and Hoeffler 2001, Collier 1998, 1999). With the notable exception of the work by Verwimp on the Genocide in Rwanda (Verwimp, 2004a, 2004b, 2003a, 2003b), few studies have used micro-level household data to look at the causes or consequences of conflict. ${ }^{1}$ At the same time, by looking at the long-run consequences of mortality, morbidity and negative educational shocks, this study can contribute to a better understanding of the fertility decisions, the marriage market and the long-term benefits associated with education and good health.

This paper is structured as follows: Section II documents the excess mortality that took place during the period and decomposes it by birth cohort, gender, and family background. Section III analyzes fertility behaviors and the marriage market. Section IV investigates the long-term impact of the period on health, while section $\mathrm{V}$ describes the consequences on the educational attainment of the population. Section VI concludes.

\section{Mortality}

Estimates of mortality under the Khmer Rouge regime vary widely and are the subject of an intense debate. Sometimes this debate is more ideological than scholarly. This is not surprising, given that the government overthrown by the Khmer Rouge, led by Lon Nol from 1970 until 1975, was pro-American, that the Khmer Rouge under Pol Pot advocated a radical form of Marxism and that the regime that took control of the country in 1979 was backed by the Vietnamese. According to former Khmer Rouge, the death toll did not exceed 20,000, while according to the Vietnamese government, there were over three million victims (Heuveline 1998).

An independent Finnish Inquiry Commission estimated the death toll at one million using demographic accounting (Kiljunen 1984). Probably the most careful exercise of demographic reconstruction, comparing the population structure before and after the mortality crisis, has been accomplished by Heuveline (1998 (a)) using 1993 electoral lists. ${ }^{2}$ He proposes, for the entire 1970-80 period, a central estimate between 2.2 million and 2.8 million, although he is not excluding values as low as 1.2 million or as high as 3.4 million.

\footnotetext{
${ }^{1}$ See also on Mozambique, Brück (2000 and 2001) and on India, Justino (2001).

${ }^{2}$ Earlier estimates based on the reconstruction approach include Ea (1981), Banister and Paige Johnston (1993) and Vickery (1984).
} 
Previous research that used the sample approach to provide an estimate of the extent of the Cambodian genocide by interviewing survivors and collecting information about death and survival in their families include Sliwinski (1995) and Kiernan (1996). However, their estimates were based on samples of convenience, limited by local constraints, which were not representative of the Cambodian population. The present paper uses data about siblings' mortality collected in the 2000 Demographic and Health Survey of Cambodia (Kingdom of Cambodia 2001). With as primary goal the assessment of maternal mortality, the survey collects information about all the siblings $(78,852$ in total) of a nationally representative sample of 15,557 women, aged between 15 and 49 in 2000. The information includes gender, date of birth, whether the sibling is still alive and, in case the sibling died, the date of death.

Even with a nationally representative sample, estimates based on a sample of survivors are potentially subject to several shortcomings (Heuveline, 1998 (b), 2001 (a), 2001 (b)). First, the method relies on recall of past events and is therefore possibly prone to misreporting. Several tests of data quality have been performed and there does not seem to be systematic reporting biases (Kingdom of Cambodia 2001): the sex ratios at birth are in the internationally acceptable range suggesting that there is no serious under or over reporting of brothers or sisters. Similarly, the median year of birth is the same for respondents as for siblings, indicating that there is no underreporting of older siblings. Another issue is the possibility of double counting: if two sisters are interviewed, the same deaths and survivals will be reported twice. Although this possibility cannot be ruled out in the data set used, this does not appear to be a major issue in a random nationwide sample. More importantly, as long as the analysis focuses on relative rather than absolute numbers, double counting of some deaths and survivals should not affect most ratios.

A more serious problem, however, is that for a family present, say in 1975 , to have a chance to be represented in 2000, at least one of the siblings need to have survived until 2000. In other words, the survey misses the families that were entirely killed during the genocide and is likely to over-sample families with many survivors. This means that the survival probabilities of brothers and sisters are not independent ${ }^{3}$ and is likely to lead to a serious underestimation of the extent of the mortality. For this reason, this study will focus on relative rather than absolute numbers, and will not attempt, as most previous studies have done, to calculate "the number", i.e. an estimate of the excess number of deaths during the Khmer Rouge period. However, in the appendix, I will, for selected

\footnotetext{
${ }^{3}$ In a simple regression, controlling for year of birth and gender, a 10 percentage point increase in the proportion of siblings that died (excluding the individual under consideration) leads to a 4 percentage point increase in the probability to have died.
} 
birth cohorts, attempt to compute death tolls using the death probabilities calculated in my analysis and baseline data provided in Heuveline (2001 (b)). This provides an idea of the extent of the underestimation caused by the sample approach. As the appendix shows a very substantial degree of underestimation, it is possible to conclude that most differences obtained using the sample approach probably represents underestimates since the families in which deaths were most likely to occur between 1975 and 1979 are underrepresented in the sample. I have also chosen not to include the respondent in the counts, but only her siblings, because otherwise mortality would be further underestimated since, by definition, respondents are all survivors. Another issue is international migration (widespread as many Cambodians took refuge in neighboring Thailand or Vietnam): to the extent that families migrated and did not come back to Cambodia and if those families experienced a different mortality rate ${ }^{4}$, this might induce some bias.

Despite these shortcomings, the mortality estimates derived from the siblings' data from a large representative sample represent a useful contribution. First, even if they underestimate the number of deaths, they provide an accurate measure of the impact of mortality on the current population structure in Cambodia. Such data also allow the analysis to address questions about the timing and the socio-economic distribution of excess mortality that cannot be answered with the reconstruction approach.

\section{II.1 Extent and timing of excess mortality}

As argued above, this section of the paper does not attempt to calculate "the number", i.e. an estimate of the excess number of deaths during the Khmer Rouge period. ${ }^{5}$ It rather describes the impact of the excess mortality during the period on the current population structure in Cambodia.

4 Information about past international migrations is scant in the Demographic and Health Survey. It is known whether a respondent always resided at the same place or not. If not, the length of the stay in the current residence and the type (urban, rural, abroad) of the previous residence is known. It is therefore possible to identify 130 respondents whose previous place of residence was abroad. The mortality experienced during the 1975-79 period by the siblings of respondents whose previous residence was abroad and later came back to Cambodia differ from the rest of the population: for all ages and genders together, their death probability for $1975-79$ was $5.09 \%$ (C.I. 3.00-7.18), while for siblings for which there is no indication that the sister migrated abroad, the death probability was $9.60 \%$ (C.I. 9.33-9.87). This seems to point to a lower mortality experience for families who migrated abroad. However, the survey gives a very incomplete picture of international migration: there is no information about when the migration took place and the survey only yields information in case it is the residence that immediately preceded the current one that was abroad. In addition, the survey misses families that migrated out of Cambodia and never came back.

${ }^{5}$ See however the appendix for a comparison between the reconstruction and the sample approach for selected birth cohorts. 
The first point to establish is that there was excess mortality during the period. Figure 1 very simply plots, without any adjustment for the number and the age of individuals at risk in each year, the number of deaths reported among siblings in each year. The period from 1974 to 1980 stands out with a number of reported deaths orders of magnitude above the preceding and following years. It should be noted that in the year 1974, mortality is concentrated during the last months of the year, while in 1980 it is concentrated during the first months. Essentially, excess mortality peaked during the period that covers the end of the Lon Nol regime when it was fighting against the Khmer Rouge (end 1974 until April 1975), the entire Khmer Rouge regime (April 1975-January 1979) and the period during which the Khmer Rouge and the Vietnamese have been fighting for the control of the country (1979-1980).

The temporal distribution of the death toll over the 1970-80 decade has also been the subject of intense debate, partly for the ideological motives mentioned above. The demographic reconstruction exercise of the type proposed by Heuveline (1998 (a)), that starts from a baseline in 1962 and a population count in 1992 does not allow to capture the timing of the deaths precisely. The method used in this paper allows to conclude that, although mortality was already high, especially in certain age groups, in the early 1970s, as well as in the early 1980s, the overwhelming part of the excess mortality has been concentrated between late 1974 and early 1980.

This point is made even clearer in figure 2 which presents a much more careful analysis than the raw data plotted in figure 1. For each five year birth cohort between 1940 and 1984, and for each five year period between 1950 and 1999, the probability to die during the five year period is plotted. Table 1 contains the underlying data, broken down by gender, with standard errors and sample sizes, for the period 1965-1989. Figure 2 confirms the conclusion that, even though mortality was high in 1970-74 and 1980-84, mortality was extreme during the 1975-79 period.

\section{2 Violent mortality: mortality by birth cohort and gender}

Mortality under the Khmer Rouge was not only due to war and executions, as famine and very poor health conditions also contributed to the excess mortality. However, the distribution of the death probabilities by birth cohort between 1975 and 1979 illustrated in figure 2 is evidence that a considerable proportion of the excess mortality is due to violent deaths, since it is not the birth cohorts most vulnerable to poor nutrition and diseases like the children, who experienced the highest mortality. Indeed, the probability of dying between 1975 and 1979 ranges between 12 and 14 percent for individuals born between 1940 and 1959, who were aged 15-34 in 1975, while individuals aged 5 to 14 in 1975 experienced a probability of dying around 6 percent and 
young children (born between 1970 and 1979) had a 10 percent probability not to survive until the end of 1979.

Figure 3 further emphasizes that point by plotting the death probability during the 1975-1979 period by birth cohort and gender. Mortality is much higher among males, but this is only true for adults. The fact that prime adult males are, by far, the most likely to die during the Khmer Rouge period indicates that violent deaths made a major contribution to excess mortality. ${ }^{6}$ The result of this differential mortality by birth cohort and gender is that there are serious imbalances in the current population structure of Cambodia, including an excess number of females especially for certain age groups.

\section{II.3 Selective mortality: mortality by socio-economic status}

It is generally believed that the Khmer Rouge targeted especially the educated and urban groups in the society, as they were seen as obstacles for the creation of a "new" society. However, this claim, based on numerous anecdotal evidence and survivors accounts has not yet been quantified very reliably. Only Sliwinski (1995) who uses, because of constraints at the time of his survey, a non representative sample of survivors (63 Cambodian households refugees in France, 589 households refugees in Thailand and 644 households in the Phnom Penh area) provides estimates of selective mortality: he indicates that more educated individuals were more likely to die between 1975 and 1979 and especially that some professions like army officers, policemen, managers and the clergy were at very high risk. He also provides estimates of mortality rates by province. Such estimates, however, based on samples of convenience, are not as reliable as estimates from a nationally representative sample.

In the siblings' data collected in the nationally representative Demographic and Health Survey, there is no direct information on the socio-economic status of the siblings. However, by using information about the respondents, it is possible to have an idea of the socio-economic status of the family. One variable indicates whether the respondent lived in a rural or an urban environment during her childhood. For women born before 1975, this allows to determine whether her family was of urban or rural origin. Given the large internal migrations that occurred under the Khmer Rouge, the strategy is less reliable for younger women. Similarly, for women who could have attended secondary school before

\footnotetext{
${ }^{6}$ This point was already made by Heuveline (1998). Sliwinski (1995), based on survivors' accounts, provides a breakdown of mortality by type of deaths (executions, famine, missing, natural and war). An interesting comparison with "normal" mortality rates by age and gender before the mortality crisis can be made by looking at the estimates by Migozzi (1973) for 1958-59 in Cambodia: at that time, the age pattern of mortality displayed the usual J-shape with very high mortality for young children, declining rapidly until adolescence and increasing thereafter, first slowly until age 50 and then more steeply. Similarly, Migozzi (1973) estimates that, because of maternal mortality, between ages 15 to 40, women were more at risk than men in 1958-59.
} 
$1975^{7}$ (secondary schools were closed under the Khmer Rouge), their schooling levels can be considered as a good indicator of the social and educational status of their family (only a minority of Cambodian girls went to secondary schools in the 1960s and early 1970s).

Table 2 implements this strategy in order to look at the mortality differentials between 1975 and 1979 by socio-economic status. The comparison between the two first columns indicates that members of a family that lived in an urban area before 1975 were more likely to die, and that this difference exists for both genders. The two last columns establish that individuals who had a sister who attended secondary school prior to 1975 were more likely to experience excess mortality. This difference is however much larger, and only statistically significant, for males. ${ }^{8}$ In the lower right corner, the table establishes that the difference by educational status of the sister is much larger and only significant among families of urban origin. Figures 4 and 5 further examine these differentials by birth cohort. Figure 4 establishes that, although the differential is higher for adults, the excess mortality among families of urban origin is present for all birth cohorts. This might be due to the fact that, as part of the Khmer Rouge "Year Zero" experiment, all major cities were evacuated by force and the urban population was relocated in the countryside. On the other hand, figure 5 shows that the differential by educational achievement of the sister prior to 1975 is concentrated among adults ${ }^{9}$, suggesting that educated adults have been especially targeted. Generally, in most developing countries, in the absence of violence targeted at them, it is expected that the urban and the educated experience a lower mortality.

\section{II.4 Infant and under-five mortality}

In Table 1, constructed from sibling's mortality data, the last row of each column shows the probability to die within the next five year period for individuals not yet born at the beginning, but who will be born during this five year interval. This can already give a raw measure of the magnitude of infant and child mortality. However, this estimate is not very reliable as, contrary to the estimates in the cells for older individuals, these children are not necessarily at risk from the beginning of the five year period. A better statistic would be the probability that each newborn survives his first year (infant mortality) and his first five years (under-five mortality). This measure can be calculated from the birth histories in the Cambodia Demographic and Health Survey, which records

\footnotetext{
${ }^{7}$ According to the breakdown in birth cohorts made in this paper, this means women born before 1960.

${ }^{8}$ Notice that the sample sizes are smaller in the last two columns because they only consider siblings of women born before 1960, while the two first columns consider siblings of women born before 1975 .

${ }^{9}$ The differences are only significant for the birth cohorts aged 30-34, 20-24 and 15-19 in 1975.
} 
for each woman interviewed data on all births, including whether the child survived and if applicable the date of death. ${ }^{10}$

Figure 6 plots the one year and the five year survival probability by birth cohort. It should be noted that infant and under-five mortality will tend to be underestimated for earlier birth cohorts. First, since, the surveys interviews women aged 15 to 49 in 2000, the mothers in this sample who gave birth in the 1970s were young at the time. The risk of infant and child mortality tends to increase in the late fertile years of a woman.

Second, given the retrospective nature of the birth histories data, only women who survived until 2000 are interviewed. Those women who did not survived until 2000 might have been more likely to have children who died as well.

Despite this underestimation of infant and child mortality for children from earlier cohorts, figure 6 shows that infant and under-five mortality was very high for children born during the 1970-1979 period. For example, a child born between 1975 and 1979, had a 14.8 percent risk of dying within his first year of life and a 22 percent chance not to make it until his fifth birthday (see the detailed data in Table 3). Compared to other birth cohorts, infant mortality peaks for the 1975-79 birth cohort and under-five mortality is higher for the $1970-74^{11}$ and $1975-79$ birth cohorts. It is also very striking that for cohorts born during the 1970s, child mortality (mortality between age one and age five) is a substantial component of under-five mortality, whereas for later birth cohorts, most of the mortality is concentrated during the first year of life. During the mortality crisis of the 1970s, the living conditions were such that survival after the first year was also problematic. The analysis did not show significant differences in the infant and underfive mortality across genders.

Figure 7 compares the one year survival probability for children with rural and urban backgrounds ${ }^{12}$ and figure 8 proceeds similarly for different schooling levels of the mother. In both cases, there was no statistically significant differences between the two groups for birth cohorts born in the 1970s, whereas, for subsequent birth cohorts, born after the mortality crisis, urban children are less likely to die (the difference is statistically

\footnotetext{
${ }^{10}$ One year and five year survival probability could also be calculated from the siblings' mortality data, but, in order to compare child mortality in 1975-79 with current levels, it is better to use information about the children than about the siblings of women aged 15-49 in 2000, as they are on average younger. Also, it is preferable to use the characteristics of the mother rather than those of the sister, as an explanatory variable.

${ }^{11}$ Notice that, especially for the probability to survive the first five years, the 1970-74 birth cohort was at risk during part of the $1975-79$ period.

${ }^{12}$ Notice that, while, when analyzing adult mortality, I used the rural/urban background of the sister during her childhood (only if she was born before 1975), in the analysis of child mortality I am using the current rural/urban location of the mother.
} 
significant, see table 3, for children born between 1980 and 1994) as well as children from mothers with at least some secondary (difference significant for all birth cohorts from 1980). Around the Khmer Rouge period, the usual advantage in terms of infant and child survival of the urban and educated was lost.

\section{Fertility and Marriage}

During a period of excess mortality, forced relocation and violence, fertility is expected to be low. Figure 9 displays the average number of births per women and per year for the two birth cohorts interviewed in 2000 that were already of fertile age in 1975. During the 1975-79 period, women born between 1950 and 1954 experienced a sharp decline in their fertility, although they were theoretically in their most fertile years. Similarly, the fertility of the 1955-59 birth cohort was very low, when compared with the 1950-54 birth cohort at the same age five years before. Combined with a high mortality rate among women, this very low fertility means that very few babies were born around the Khmer Rouge period.

However, very shortly after the end of the Khmer Rouge rule, Cambodia experienced a "baby boom" as illustrated on figure 9. During the early 1980s, fertility rebounded dramatically, reaching, for the two birth cohorts analyzed a probability to give birth during the year above 30 percent. Heuveline (2003) provides a detailed analysis of the Cambodian baby-boom, based on preliminary data collected by the Mekong Island Population Laboratory.

One of the main determinant of fertility is marriage. Figure 10 shows for the three birth cohorts that were of nuptial age in 1980, the probability that the first marriage occurred in any specific year. This probability was relatively low for each birth cohort during the 1975-79 period. The striking feature is however the very high marriage rates in 1979 and 1980 for the birth cohorts born in 1955-59 and 1960-64. The probability to have the first marriage peaks dramatically for both cohorts in the same year -1979 - whereas one would have expected, under normal circumstances, that the peaks for the two cohorts would have been five years apart. Similarly, the peak for the 1950-54 birth cohort is in 1970, nine years before the peak for the subsequent birth cohort. It seems therefore that the women who according to their age were most likely to marry for the first time during the Khmer Rouge period delayed their marital prospects.

Young adult males were among the most likely victims of the excess mortality during the Khmer Rouge period, as demonstrated in figure 3. In the early 1980s, there was therefore a large shortage of young males on the marriage market. However, it does not seem that this led to a large fraction of unmarried women: by 2000 , not more than 
five percent of the women born between 1950 and 1964 had never been married. One way the marriage market seems to have adapted to the unbalance is for the age difference between partners to have been reduced. Figure 11 displays by birth cohort the average age difference between partners. ${ }^{13}$ The birth cohorts aged 10-14 and 15-19 in 1979, the ones that would get married in the subsequent decade, have a lower age difference with their partner than the preceding and subsequent birth cohorts. Table 4 also reports that the same birth cohorts of women are more likely to have a partners younger than them. The evolution of the schooling differences between partners across birth cohorts, reported in table 4 and plotted in figure 11, is also interesting: the average schooling difference between partners is at its lowest point for women aged 5 to 14 in 1979. As shown in sections II and V, the Khmer Rouge period had also lasting impacts on average educational attainment of individuals: educated individuals, especially males, were more likely to die and individuals, again males in particular, who were of schooling age during the period have much lower schooling levels than preceding and subsequent birth cohorts. In the years following 1979, there was therefore a shortage of educated men eligible for marriage and the average schooling attainment of men and women became closer.

After the mortality crisis of the 1970s, two potentially opposite forces were thus characterizing the Cambodian marriage market: on the one hand, eligible males were in short supply, reducing the choice opportunities for females, but, on the other hand their age and schooling differences with their husbands decreased, which should have increased their bargaining position inside the household. Heuveline and Poch (2004) study the impact of the low male to female ratio on marital outcomes, but do not find evidence that it increased marital instability.

\section{Health and Disability}

Since the Khmer Rouge period was a period of war, starvation and violence, it is reasonable to expect that it had an impact not only on mortality but also on morbidity. This section attempts to measure the long term consequences of the period on the health status of Cambodians in 2000.

Poor nutrition during childhood and adolescence are likely to result in stunting. The Cambodian Demographic and Health Survey contains anthropometric measurements of women aged 15 to 49 . Figure 12 plots the average height and the proportion of women above $150 \mathrm{~cm}$ (women under $150 \mathrm{~cm}$ are considered to be at nutritional risk). Women

\footnotetext{
in table 4 .
}

${ }^{13}$ The variable is the age of the current partner, not necessarily the first husband. The data is reported 
aged 35 to 39 in 2000, i.e. in their early teens in 1975, seems to be the shortest and the most likely to be stunted. It is not surprising, given that nutrition during adolescence is an important determinant of stature, that this birth cohort was especially vulnerable. However, it is somewhat surprising that women from birth cohorts that were young children in 1975-79 do not appear to have suffered from stunting compared to the other cohorts. One potential hypothesis to explain this could be that poor nutrition during the 1975-79 period in early childhood was likely to end in death, as evidenced by the very high under-five mortality rates (see figure 6), while for teenagers, it was more likely to result in stunting. It should be noted, however, as reported in table 5, that most of the differences in stature across birth cohorts are not statistically significant.

Figure 13 shows the rate of permanent disability and physical impairment by gender and birth cohort. The disability rate is much larger for males than for females for the birth cohorts who experienced the Khmer Rouge period as children, teenagers or young adults (older than 30 in 2000). This is explained by a greater exposure to landmines and weapons: the line with triangles in figure 13 shows the proportion of the disabilities among males that are due to a bomb, a landmine or a weapon and this proportion explains most of the gender differential in the disability rates after age 30 . The data are in table 6 which also reports the percentage of individuals, by birth cohort and gender, who reported to have suffered from an illness or an injury in the last 30 days preceding the survey. There does not seem to be any particular pattern in the differences across birth cohorts and gender that would reflect the long term impact of the Khmer Rouge period on self-reported illnesses.

\section{Education}

The Cambodian school system was ruined during the Khmer Rouge period. Only basic primary schools, with a curriculum centered on agricultural skills, were open and no secondary schools were in operation. Table 7, adapted from Kiljunen (1984) indicates how, right after 1979, the secondary school system was in despair, with only a few hundred teachers for the whole country. Desbarats (1995) also provide a similar account of a very low enrollment in secondary schools during the school year 1979/80 with a gradual increase over the 1980s.

Figures 14 and 15, using data from the 2001 Cambodia Labor Force Survey ${ }^{14}$, show that the individuals who were of secondary schooling age at the end of the 1970s have a lower level of educational achievement than the preceding and subsequent birth

\footnotetext{
${ }^{14}$ The same result can be found using the Demographic and Health Survey of 2000 and the Cambodia Socio-Economic Survey of 1997. Results available on request.
} 
cohorts. Both average years of education and, even more dramatically, the proportion of individuals who have at least some secondary education are much lower for individuals who were teenagers in 1975. This is especially marked for males (the differences are only statistically significant for males and for both gender together, not for females). Since, among the young adult males in 1975, the educated have been especially targeted by the violence and the mortality, as shown in figure 5, it is also likely that the difference between the teenagers in 1975 and the preceding birth cohorts would have been even larger in the absence of selective mortality of the highly educated.

As a consequence of the collapse of the school system, a large number of children were not allowed to attend secondary school, even though they might have been willing to. Once the reconstruction of the country and the school system started, they were older and had probably many other priorities. This constitutes an exogenous shock to educational attainment. Initially, the aim of this paper was to attempt to use this exogenous variation to identify the labor and non labor market returns to schooling. The preceding analysis has shown that, if the exogenous variation in education is only defined at the birth cohort level, the exclusion restriction, i.e. the condition that the birth cohort only affects the outcomes of interest, like earnings or health, through education, is not likely to be satisfied. Indeed, mortality, violent death, fertility, marriage and disability rates are all strongly affected by birth cohort effects. If in addition to the cohort related variation, I could rely on some exogenous geographical variation in schooling, this approach might be more appealing ${ }^{15}$. I will try to find and use data about school reopenings or reconstruction after the Khmer Rouge period to make progress on this strategy. However, this approach would only be valid if the geographical variation in education proves not to be correlated with geographical variations in mortality or other outcomes.

\section{Conclusions and Further Research}

This paper studies the long-term impact of genocide during the Khmer Rouge regime (1975-79) in Cambodia. This study uses the siblings' mortality data from the Cambodia Demographic and Health Survey in 2000 for quantitative analysis. It shows that excess mortality was extremely high and heavily concentrated during the 1974-1980 period. Adult males were the most likely to die, indicating that violent death played a major role. The paper also establishes that individuals from a family with an urban or an

\footnotetext{
${ }^{15}$ A similar approach is developed by Giles, Park and Zhang (2004) for disruptions to education during the Chinese Cultural Revolution. Approaches based solely on birth cohort effects are Meng and Gregory (2002 (b)) for China during the Cultural Revolution and Ichino and Winter-Ebmer (1998) for Austria and Germany after World War II.
} 
educated background were more likely to die. This confirms the claims made by historians that the educated and the urban population were especially targeted. Infant mortality was also at very high levels during the period. Disability rates from landmines or other weapons are also high for males who were exposed to risk during the Khmer Rouge period.

The very high and selective mortality had a major impact on the population structure of Cambodia. Fertility and marriage rates were very low under the Khmer Rouge but rebounded immediately after the regime collapsed. Because of the shortage of eligible males, the age difference between partners tended to decline.

The Khmer Rouge period had long-term impacts on the educational attainment of the Cambodian population. The mortality rates were higher among the educated population and the education system collapsed during the period, so that individuals that were of schooling age during the interval now have a lower educational attainment than the preceding and subsequent birth cohorts.

In further research, I hope to be able use a geographical variation in the rate at which schools have been closed and reconstructed in order to exploit the exogenous shock to education levels that occurred under the Khmer Rouge without having to rely only on birth cohort effects. Indeed, this study has shown that, because of the different impact of the genocide on each birth cohort and gender, the negative shock on schooling attainment experienced by teenagers during the period of the genocide would not, as such, satisfy the conditions to be a valid instrument. I will also further investigate the fertility dynamics and the matching processes in the marriage market during and after the genocide.

Finally, this paper shows that the use of the siblings' mortality and birth history data available in the Cambodia Demographic and Health Survey can be a very interesting source to analyze the magnitude and long-term impacts of a past mortality crisis. I am planning to use this approach for other countries that experienced a large mortality crisis in the past and for which similar data have been collected. 


\section{Appendix}

\section{Estimating mortality: A comparison between the sample based approach and the reconstruction approach}

This paper uses the sample based approach to estimate the impact of the mortality from the Khmer Rouge period on the current Cambodian population structure. To the best of my knowledge, it is the first to do so with a nationally representative sample of women interviewed about the birth, survival and deaths of all their siblings. However, this sample, interviewed more than 20 years after the mortality crisis is by definition a sample of survivors and, as such, as already explained in section II, likely to substantially underestimate mortality, since families in which all siblings died will not be included in the counts and, similarly, families which experienced a large proportion of casualties are less likely to be included in the sample. Families with a large migration rate are also less likely to be counted.

This appendix attempts to quantify the degree of underestimation of the mortality crisis by comparing death counts obtained using the death probabilities calculated from our sample of survivors with excess mortality estimates obtained using the reconstruction method. The most careful reconstruction exercise has been realized by Heuveline (1998 (a), 1998 (b), 2001 (a), 2001 (b)). He estimated, as baseline, the 1970 population of Cambodia by projecting the data from the 1962 census. He estimated the 1980 population by projecting backward data from 1993 electoral lists. Using "normal" mortality parameters and estimates of migratory flows, he then projected forward his 1970 estimate into 1980 and backward his 1980 estimate back to 1970. From both projections, the residual between the projection under "normal" parameters and the actual estimate can be computed. The average of the forward and the backward projection residuals is then presented as the number of excess deaths.

The results of the comparison are presented in table A1. For six birth cohorts born between 1940 and 1969 for which the sample based approach could provide reliable estimates of the death probabilities, the initial 1970 population for males and females is taken from Heuveline (2001(b)) and reported in columns 1 and 2. Notice therefore that, in this exercise, the sample and the reconstruction approaches start from the same baseline and so differences between estimates cannot come from this source. In columns 3 and 4, death probability during the 1970-74 period by gender and birth cohorts are taken from my estimates in table 1 . The multiplication of columns 1 with 3 and 2 with 4 respectively yields the number of deaths, while a simple subtraction from columns 1 and 2 yields the 
population remaining on January $1^{\text {st }}, 1975$, in columns 7 and 8 , assuming migration away. The same exercise can then be repeated using the 1975-79 death probabilities reported in columns 9 and 8 . The number of casualties during the 1975-79 period is then computed in columns 11 and 12 and added to the 1970-74 death tolls to give the 1970-79 figures in columns 13 and 14. These figures can then be compared with the excess deaths figures reported by Heuveline (2001 (b)) for the period from January $1^{\text {st }} 1970$ until January $1^{\text {st }} 1980$, reported in columns 15 and 16 . The ratio of both figures is computed in columns 17 and 18.

Table A1 indicates that when the Heuveline's reconstruction is used as a benchmark, the sample based method very substantially underestimates the extent of mortality. The ratios in columns 17 and 18 indicate that the sample based method would only account, depending on gender and birth cohorts, for between $28 \%$ and $65 \%$ of the mortality figures obtained using the reconstruction method. If one considers that the denominator in these ratios is only "excess deaths" while the numerator is supposed to represent all deaths, the underestimation is actually even worse. It also seems that the mortality of younger cohorts is more underestimated than for older cohorts, and also that female mortality estimates suffer from a somewhat larger bias than estimates for males.

Several factors can account for such large differences in the estimates of the extent of mortality. First, it should be emphasized that in computing the ratios in columns 17 and 18, both the numerator and the denominator were point estimates within substantial confidence intervals. The death probabilities reported in columns 3, 4, 9 and 10, are all estimated with standard errors reported in table 1. Heuveline (1998(a), 2001(b)) also report central estimates within a substantial range. However, the general pattern of underestimation by the sample based approach seems to reveal a more substantial bias not explained by the regular variance of estimates.

Heuveline (2001(b)) indicates that reconstruction approaches using "two population estimates are sensitive to the underestimation or overestimation of population size at the beginning of the period relative to population size at the end of the period, and to migration, the other cause of changes in cohort size". Since in the current exercise the same baseline population for 1970 was used, discrepancies could come from an underestimation of the 1980 population by Heuveline (2001(b)). After examining in detail his analysis, I have no elements that point in this direction. Estimates of net migration are always difficult to get, especially during chaotic times like the Khmer rouge period in Cambodia. Heuveline (1998(a)) gathers ancillary data and uses a midrange estimate. Some of the variation between our estimates might plausibly come from an underestimation by Heuveline (2001(b)) of migration out of Cambodia between 1970 and 1979. On the other hand, my own estimates, based on the sample approach do not 
take into account migration flows: if I was able to estimate the net number of migrants out of Cambodia between 1970 and 1974, this would probably reduce the population remaining in the country in 1975 and therefore further reduce the mortality estimates for the 1975-79 period. Another potential problem with a sample of survivors after a mortality crisis is that the fate - death or survival - of some of their siblings might be unknown to the respondents. However, for only 1.38 percent of siblings born before 1980 was the respondent unable to answer whether they were dead or alive. ${ }^{16}$

But, as explained above, the most likely explanation for the underestimation by the sample approach is that the data used is, by definition, a sample of survivors. The goal of this appendix was to provide an estimate of the extent of the downward bias. Since this bias is very substantial, it should be emphasized that this paper, and this appendix in particular, do not constitute an attempt to provide another estimate of "the number", an estimation of casualties under the Khmer Rouge regime in absolute terms.

On the other hand, the downward bias inherent to the sample based approach, should not necessarily affect relative comparisons of mortality patterns across different population groups. Actually, although it is difficult to quantify the extent of the bias, it is very likely that the sample based approach would underestimate differences in mortality across socio-economic groups of the type illustrated by figures 4 and 5, since, if families with an urban or educated background were more likely to be victims, they are probably underrepresented in the sample of survivors. Finally, to the extent that the downward bias implied by the sample approach is larger for younger cohorts and for females, as seems to be indicated by columns 17 and 18, this might imply that the some of the comparisons across genders and birth cohorts like in figure 3 should be revised, without, however, changing the main conclusion that young adult males were disproportionately at risk between 1975 and 1979 .

${ }^{16}$ This proportion might have been larger if, rather than in 2000, the survey had been conducted a few years after the crisis when it was still difficult for families to reunite and for information to circulate. 


\section{Bibliography}

The word "processed" describes informally reproduced works that may not be commonly available through library systems.

Banister, J., and E. Paige Johnson. 1993. "After the nightmare: the population of Cambodia." In B. Kiernan, ed., Genocide and Democracy in Cambodia: The Khmer Rouge, the United Nations and the International Community. Monograph Series 41. New Haven: Southeast Asia Studies, Yale University.

Brück, Tilman. 2000. "The Economics of Civil War in Mozambique.” In J. Brauer and K. Hartley, eds., The Economics of Regional Security: NATO, the Mediterranean and Southern Africa. Harwood Academic Publishers, Amsterdam.

Brück, Tilman. 2001. "Mozambique: the Economic Effects of the War." In F. Stewart and E.V.K. Fitzgerald, eds., War and Underdevelopment. Vol. 2. Oxford University Press, Oxford.

Chandler, D. 1996. A History of Cambodia, $2^{\text {nd }}$ ed., updated. Boulder, Colorado: Westview Press, Inc.

Collier, Paul. 1998. "On Economic Causes of Civil War." Oxford Economic Papers 50(4):563-73.

Collier, Paul. 1999. “On Economic Consequences of Civil War.” Oxford Economic Papers 51: 168-83.

Collier, Paul, and Anke Hoeffler. 2001. "Greed and Grievance in Civil wars.” Working Paper Series 2002-01. Center for the Study of African Economies, Oxford, U.K.

Collier, Paul, Lani Elliott, Håvard Hegre, Anke Hoeffler, Marta Reynal-Querol, and Nicholas Sambanis. 2003. Breaking the Conflict Trap: Civil War and Development Policy. World Bank and Oxford University Press.

Desbarats, Jacqueline. 1995. Prolific Survivors. Population Change in Cambodia 19751993. Tempe, Arizona: Arizona State University.

EA Meng-Try. 1981. "Kampuchea: A Country Adrift.", Population and Development Review 7 (2): 209-28.

Giles John, Albert Park, and Juwei Zhang. 2004. “ The Great Proletarian Cultural Revolution, Disruptions to Education, and Returns to Schooling in Urban China.”. Processed.

Heuveline, Patrick. 1998 (a). “'Between one and three million' : Towards the demographic reconstruction of a decade of Cambodian history (1970-79)." Population Studies 52: 49-65.

Heuveline, Patrick. 1998 (b). "L'insoutenable incertitude du nombre : estimation des décès de la période Khmer rouge." Population 53(6) : 1103-17. 
Heuveline, Patrick. 2001(a). “Approaches to Measuring Genocide: Excess Mortality During the Khmer Rouge Period.” In D. Chirot and M. Seligman, eds., Ethnopolitical Warfare. Causes, Consequences and Possible Solutions. Washington D.C.: American Psychological Association.

Heuveline, Patrick. 2001(b). “The Demographic Analysis of Mortality Crises: The Case of Cambodia, 1970-1979." In H. E. Reed and C. B. Keely, eds., Forced Migration and Mortality. Washington, D.C.: National Academy Press.

Heuveline, Patrick. 2003. "Mortality and Fertility Interactions: New Insights from Recent Population Dynamics in Cambodia." Processed.

Heuveline, Patrick, and Poch, Bunnak. 2004. "Individual and Structural Determinants of Marital Stability: Matchmaking, Gender Ratio, and Modernization in Cambodia." Processed.

Ichino, Andrea, and Rudolf Winter-Ebmer. 1998. "The Long-Run Educational Cost of World War II: An Example of Local Average Treatment Effect Estimation." Center for Economic Policy Research Discussion Paper No. 1895. London, United Kingdom.

Ichino, Andrea, and Rudolf Winter-Ebmer. 2004. "The Long-Run Educational Cost of World War II." Journal of Labor Economics, 22: 1, 57-86.

Justino, Patricia. 2001. "Redistribution, Political Conflict and Development in India: The Case of Kerala." Laboratoire d'Economie d'Orleans Working Paper 2001-5.

Kiernan, B. and C. Boua. 1982. Peasants and politics in Kampuchea, 1942-1981. London: Zed Books, New York: Sharpe.

Kiernan, Ben 1993. "Introduction." in B. Kiernan, ed., Genocide and Democracy in Cambodia: The Khmer Rouge, the United Nations and the International Community. Monograph Series 41. New Haven: Southeast Asia Studies, Yale University.

Kiernan, Ben 1996. The Pol Pot Regime. New Haven and London: Yale University Press.

Kiernan, Ben. 2003. "The Demography of Genocide in Southeast Asia. The Death Tolls in Cambodia, 1975-79, and East Timor, 1975-80.” Critical Asian Studies 35:4, 585-97.

Kiljunen, Kimmo, ed. 1984. Kampuchea: The Decade of the Genocide. Report of a Finnish Inquiry Commission. London: Zed Books.

Kingdom of Cambodia and ORC Macro. 2001. Cambodia Demographic and Health Survey 2000. National Institute of Statistics, Directorate General for Health and ORC Macro. Phnom Penh, Cambodia, and Calverton, Maryland.

Meng, Xin, and R.G. Gregory. 2002 (a). "The Impact of Interrupted Education on Subsequent Educational Attainment: A Cost of the Chinese Cultural Revolution." Economic Development and Cultural Change 50(4): 935-959. 
Meng, Xin, and R.G. Gregory. 2002 (b). "Exploring the Impact of Interrupted Education on Earnings: the Educational Cost of the Chinese Cultural Revolution." Processed, Australia National University.

Migozzi, Jacques. 1973. Cambodge. Faits et Problèmes de Population. Paris : Editions du Centre.

Prescott, Nicholas, and Menno Pradhan. 1997. "A Poverty Profile of Cambodia." World Bank Discussion Paper No. 373. World Bank. Washington, D.C.

Sliwinski, Marek. 1995. Le Génocide Khmer Rouge: Une Analyse Démographique. Paris : L'Harmattan.

Verwimp, Philip. 2003 (a). "The Political Economy of Coffee, Dictatorship and Genocide.” European Journal of Political Economy 19: 161-81.

Verwimp, Philip. 2003 (b). "Testing the Double Genocide Thesis for Central and Southern Rwanda." Journal of Conflict Resolution 47: 423-42.

Verwimp, Philip. 2004 (a). "Death and Survival during the 1994 Genocide in Rwanda." Population Studies 58: 233-45.

Verwimp, Philip. 2004 (b). "An Economic Profile of Peasant Perpetrators of Genocide." Journal of Development Economics. Forthcoming.

Vickery, M. 1984. Cambodia, 1975-1982. Boston: South End Press. 

Figure 1: Number of deaths by year among siblings of women age 15-49, Demographic and Health Survey 2000, Cambodia

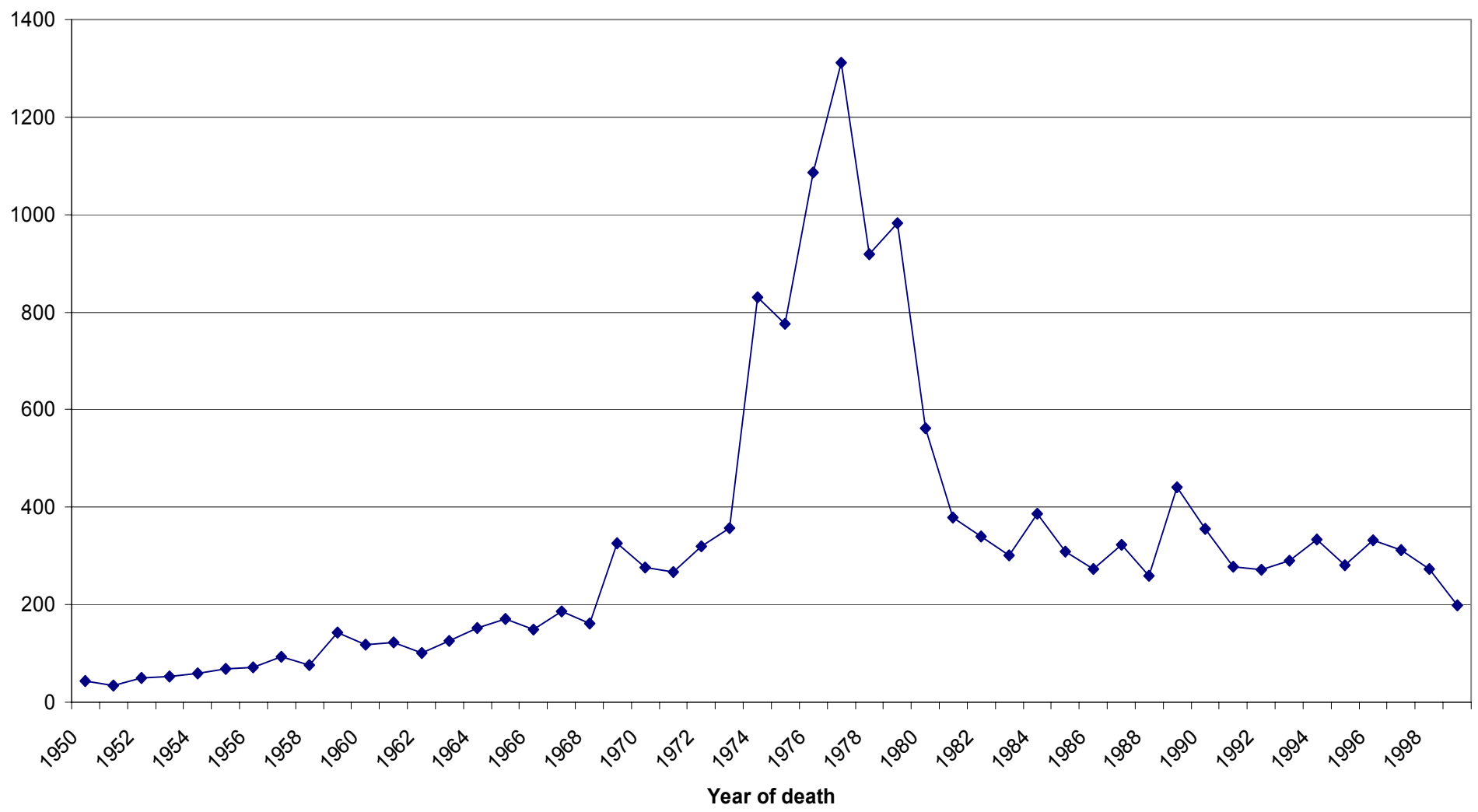

21 
Figure 2: Probability of dying during a 5 year period, by birth cohort, Cambodia DHS 2000, Siblings' mortality data

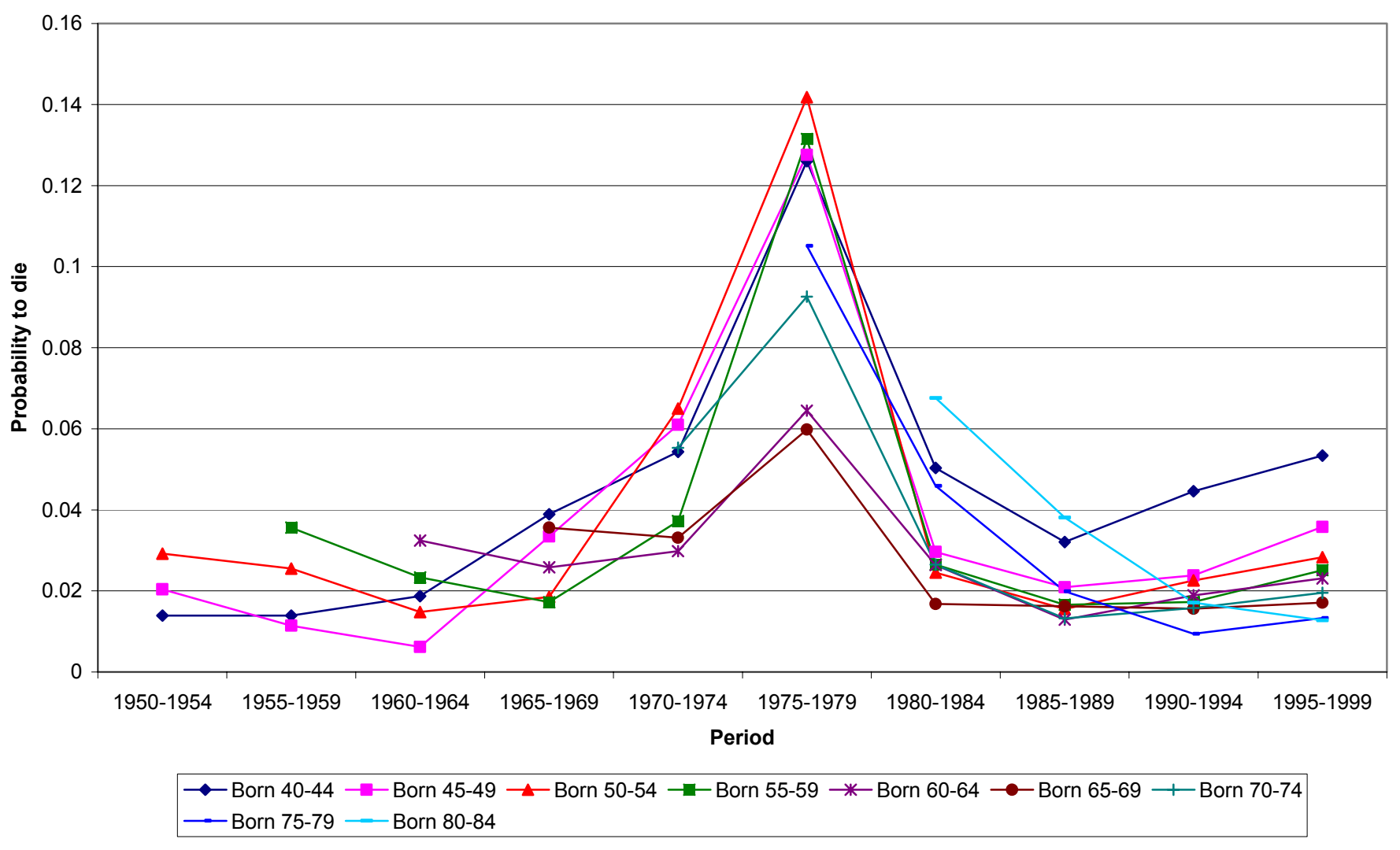


Figure 3: Probability to die between 1975 and 1979, by birth cohort and gender. From siblings' mortality data, DHS Cambodia 2000.

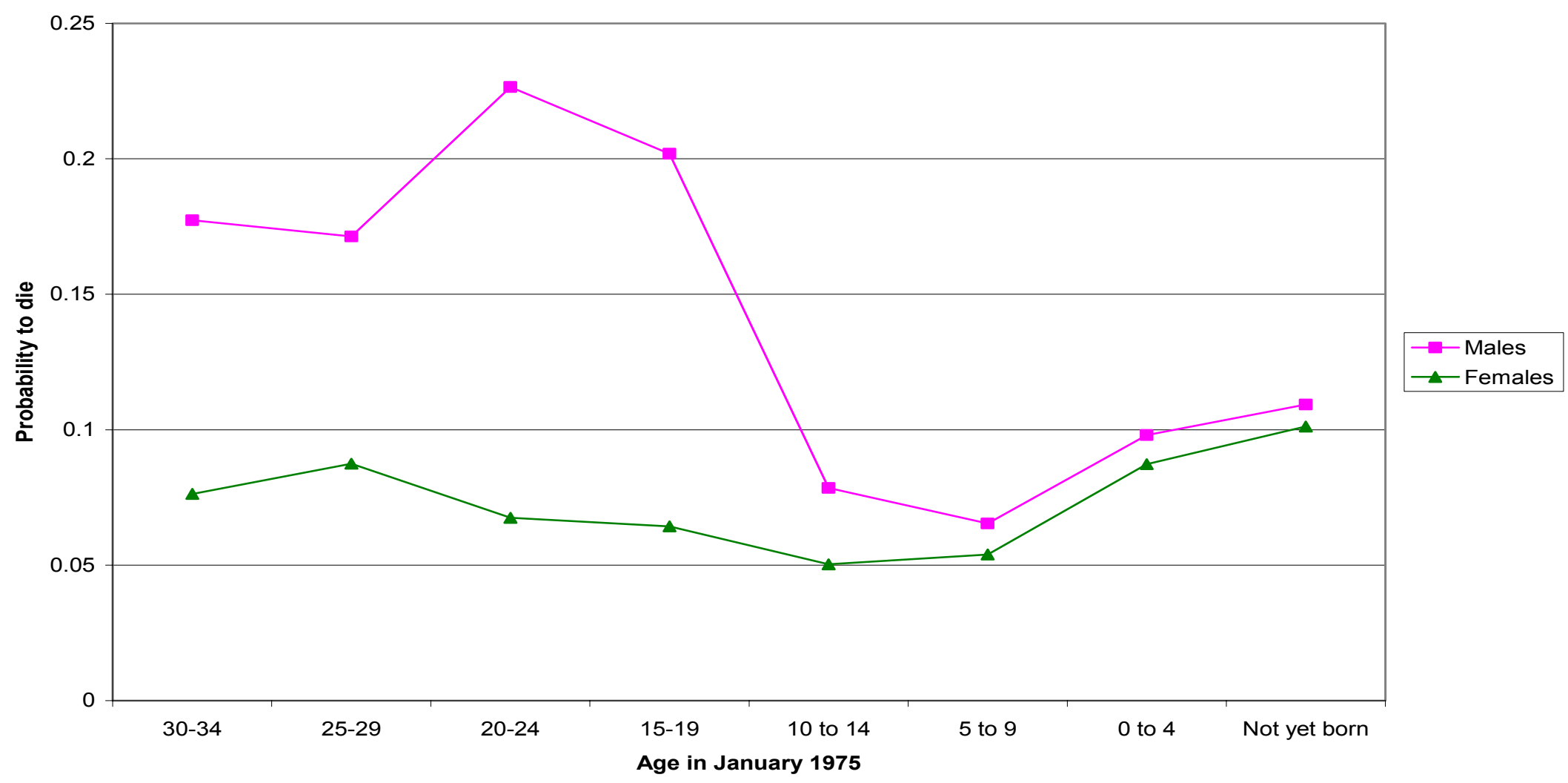


Figure 4: Mortality during the 1975-1979 period in Cambodia, by birth cohort and area of origin of the family. From sibling's mortality data, DHS Cambodia 2000.

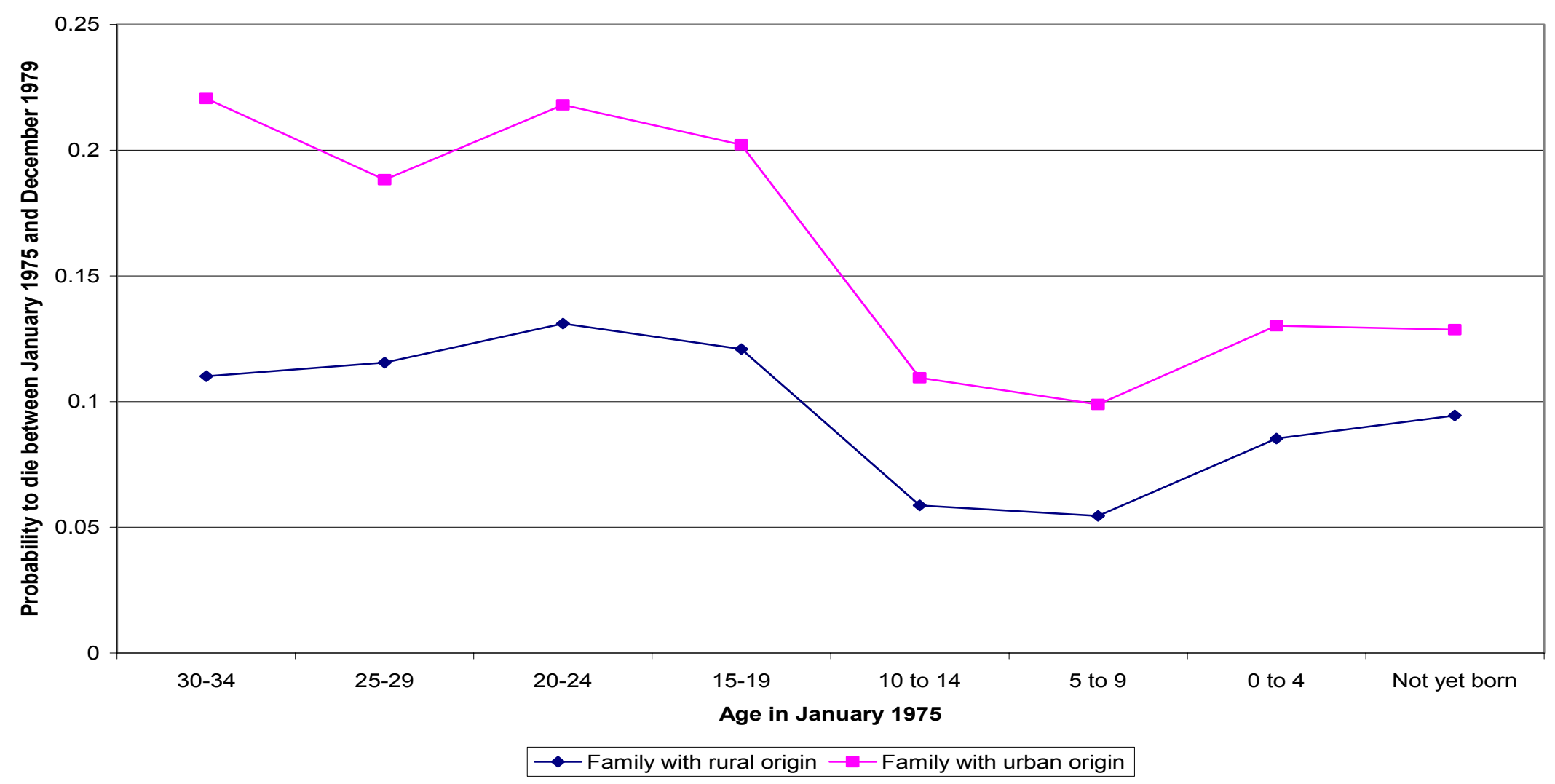


Figure 5: Mortality between 1975 and 1979 in Cambodia by birth cohort and education level of the sister. From siblings' mortality data, DHS Cambodia 2000

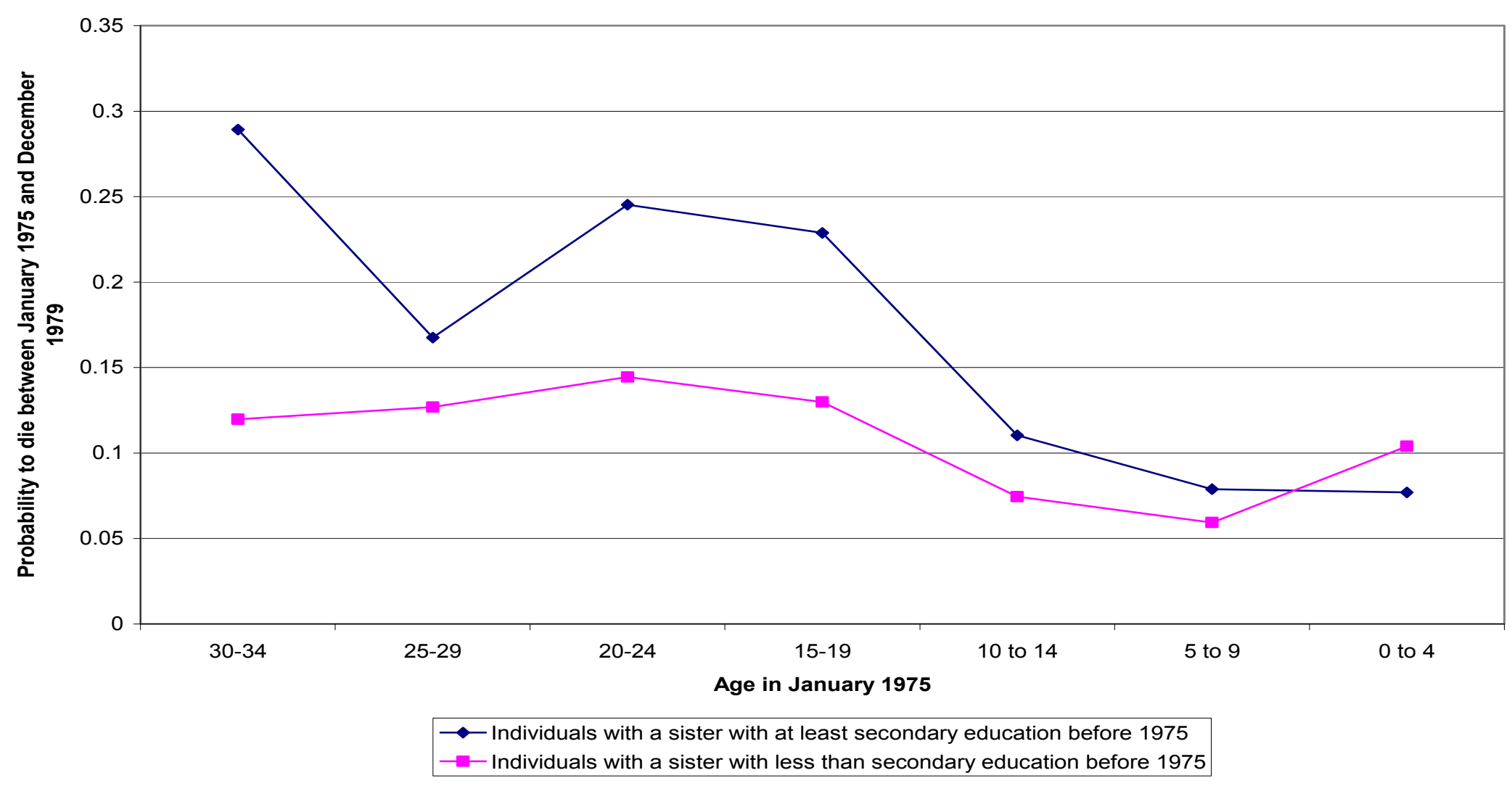


Figure 6. Infant and Child mortality: One year and five years survival probability, by birth cohort. From birth histories in the Demographic and Health Survey 2000 Cambodia.

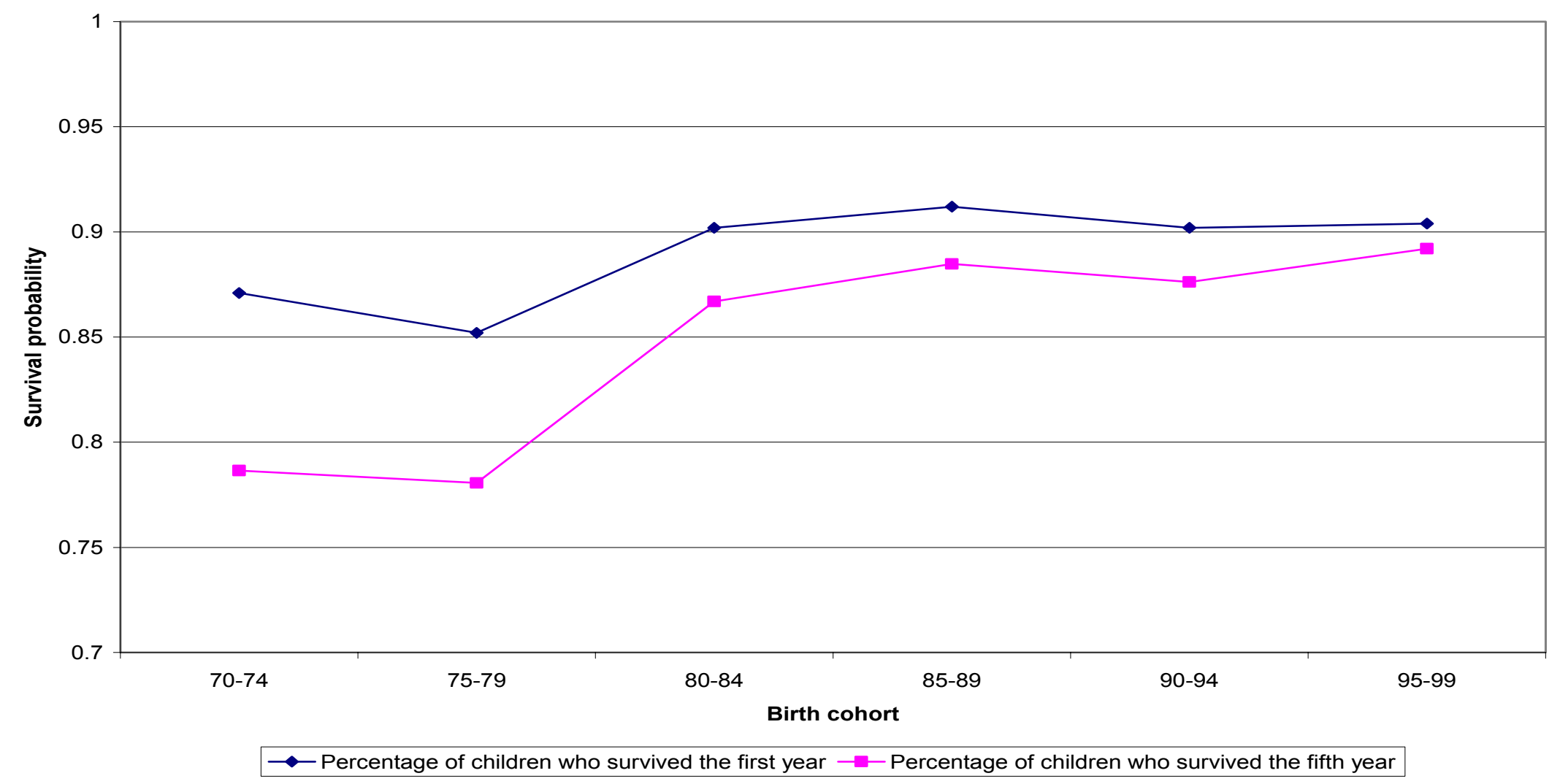


Figure 7: One year survival probability for infants, by birth cohort and location.

From birth histories in the Cambodia Demographic and Health Survey 2000

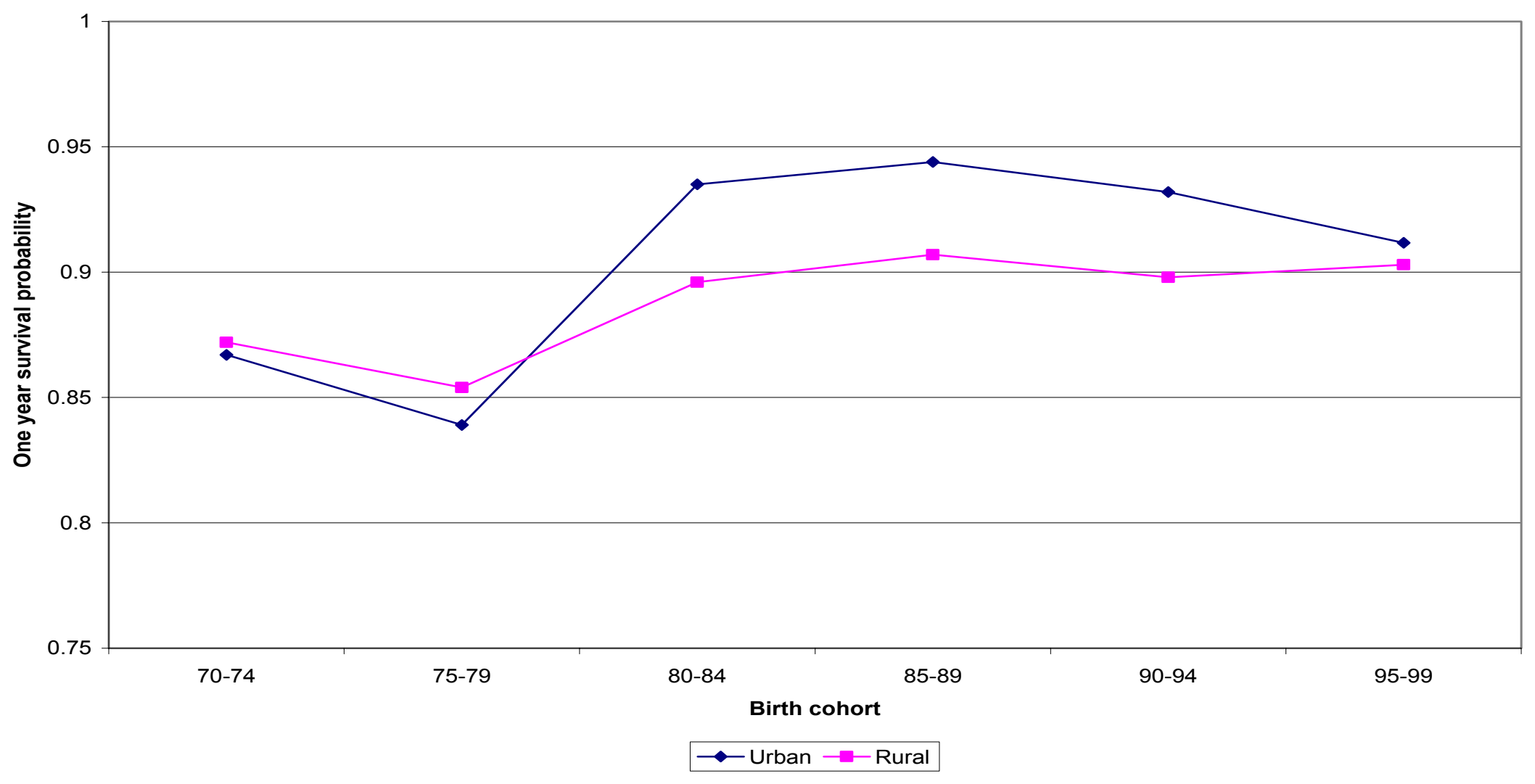


Figure 8: One year survival probability for infants by education of the mother, from birth histories in the Cambodia Demographic and Health Survey 2000

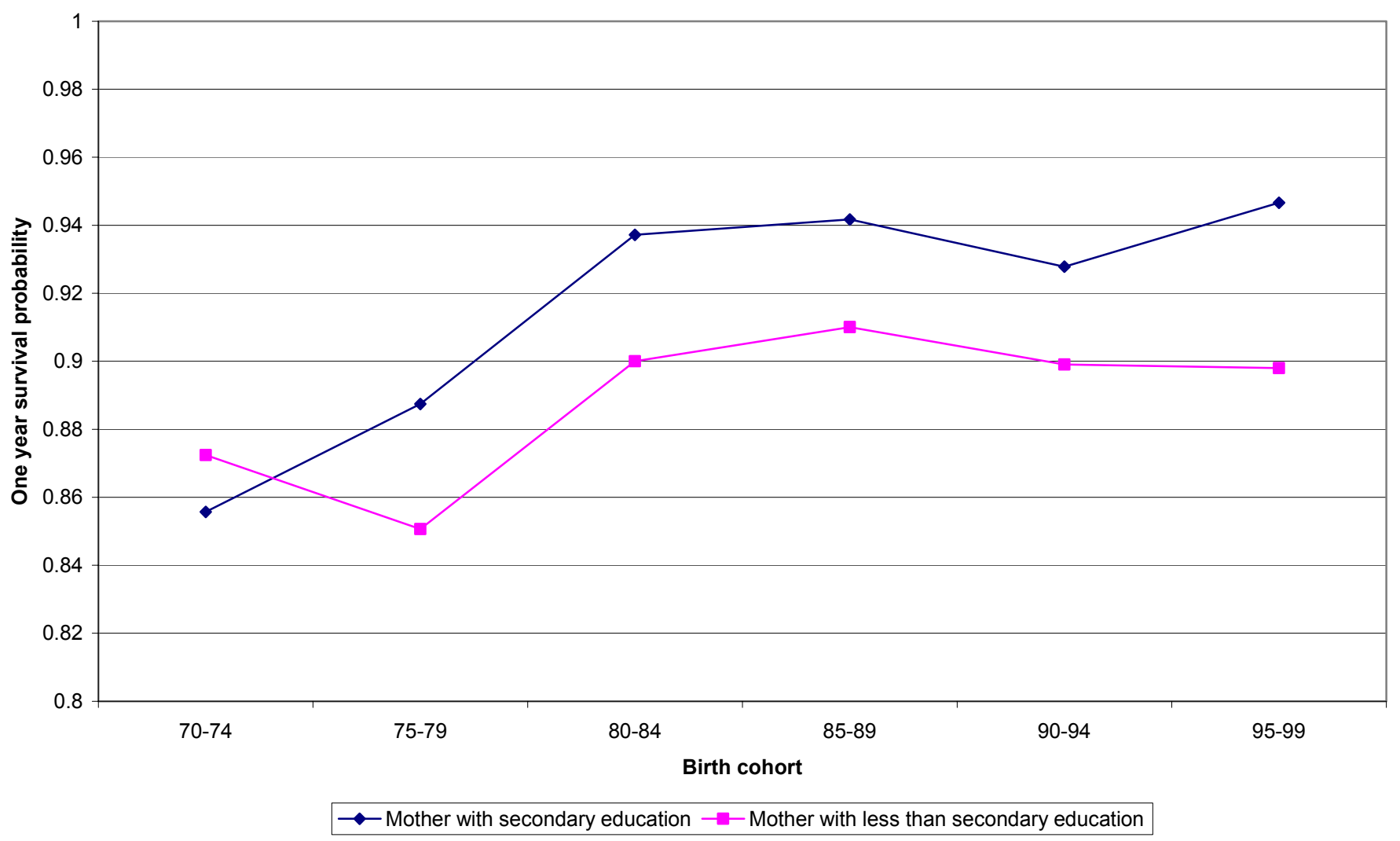


Figure 9: Number of births per woman and per year, by year and birth cohort. From birth histories in the Cambodia Demographic and Health Survey 2000

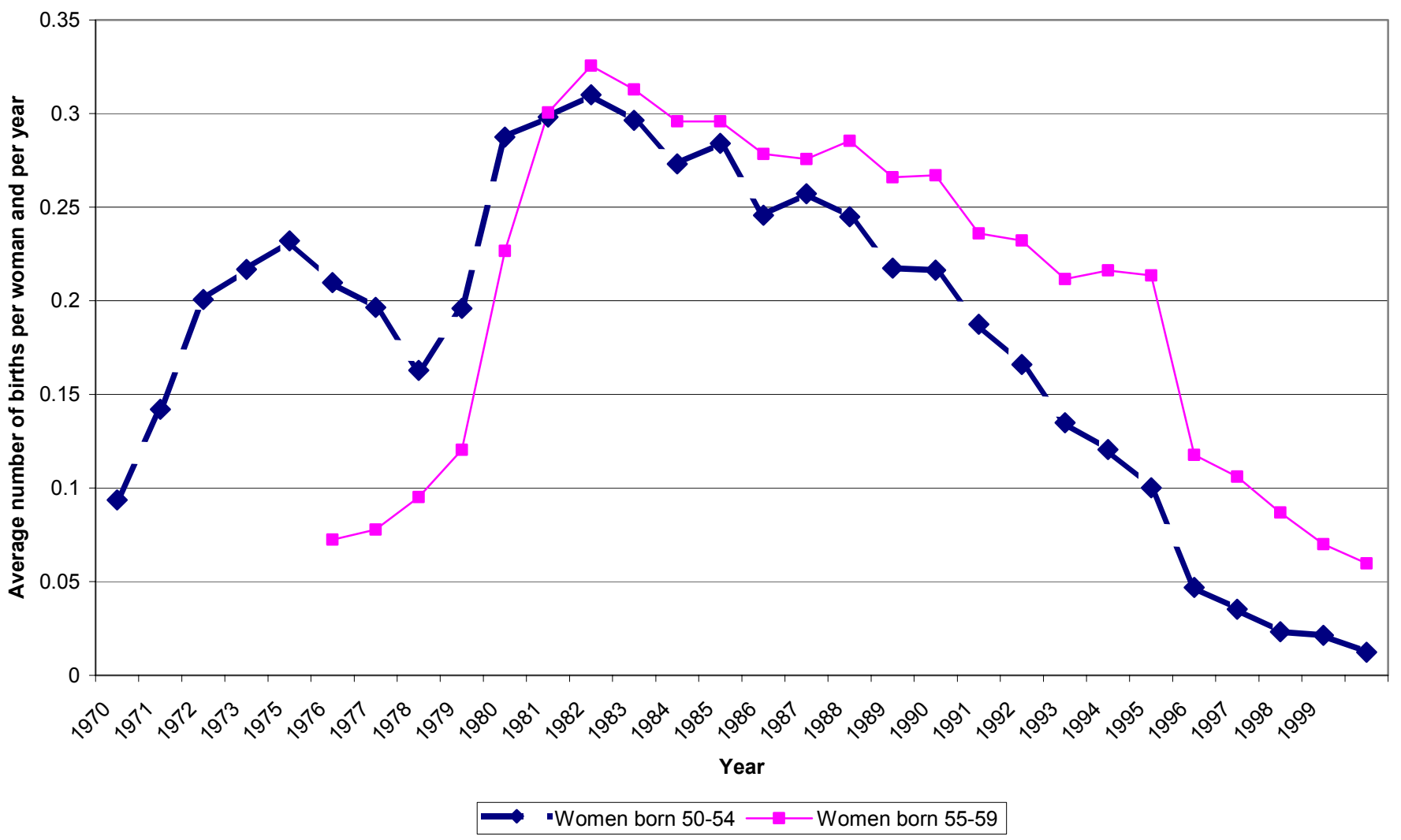

29 
Figure 10: Probability of being married for the first time, by year and birth cohort, Cambodia Demographic and Health Survey 2000

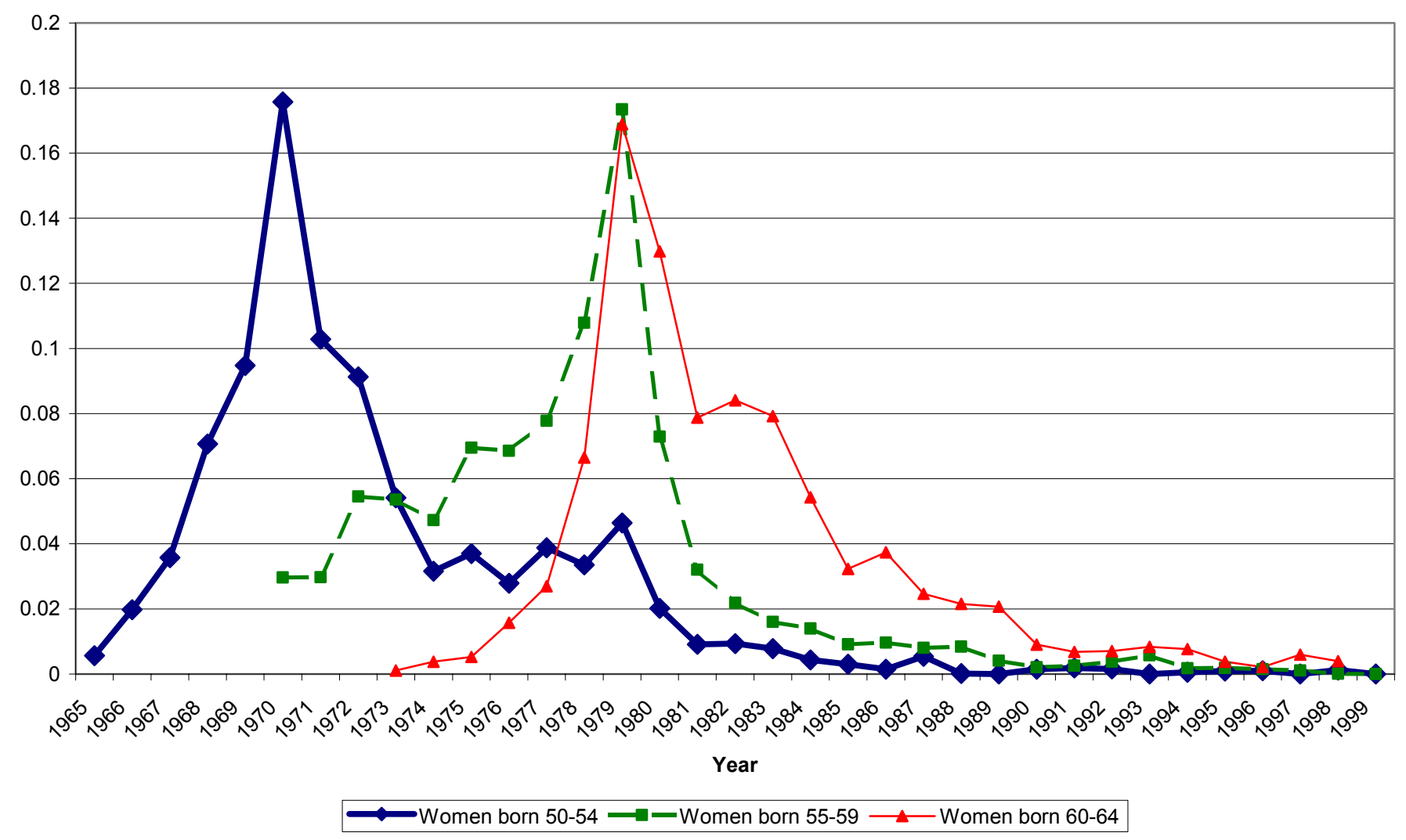


Figure 11: The marriage market: age and schooling differences between partners, by birth cohort of the wife. Cambodia, Demographic and Health Survey 2000.

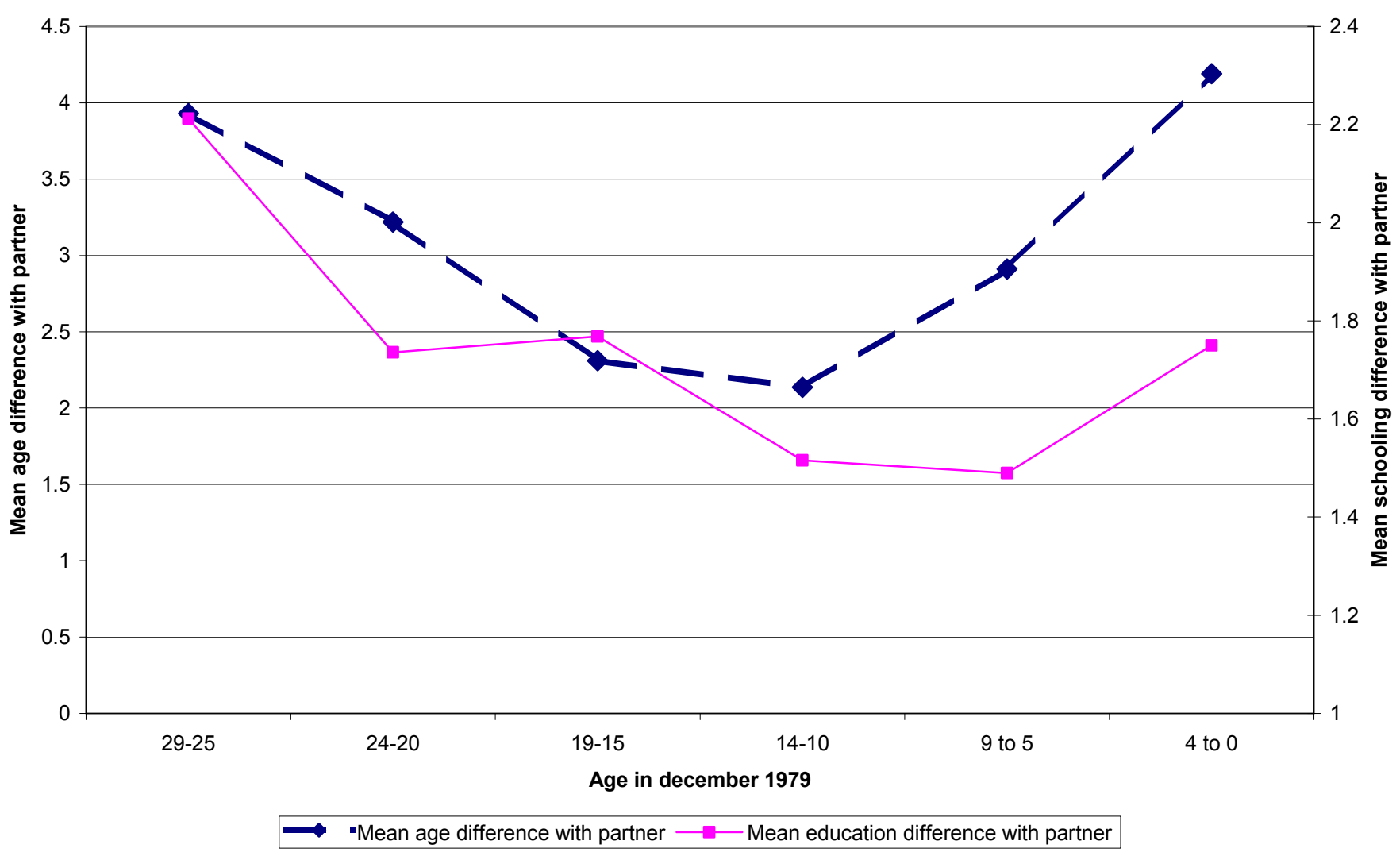


Figure 12: Average height and percentage above $150 \mathrm{~cm}$, women age 15-49, Cambodia Demographic and Health Survey 2000

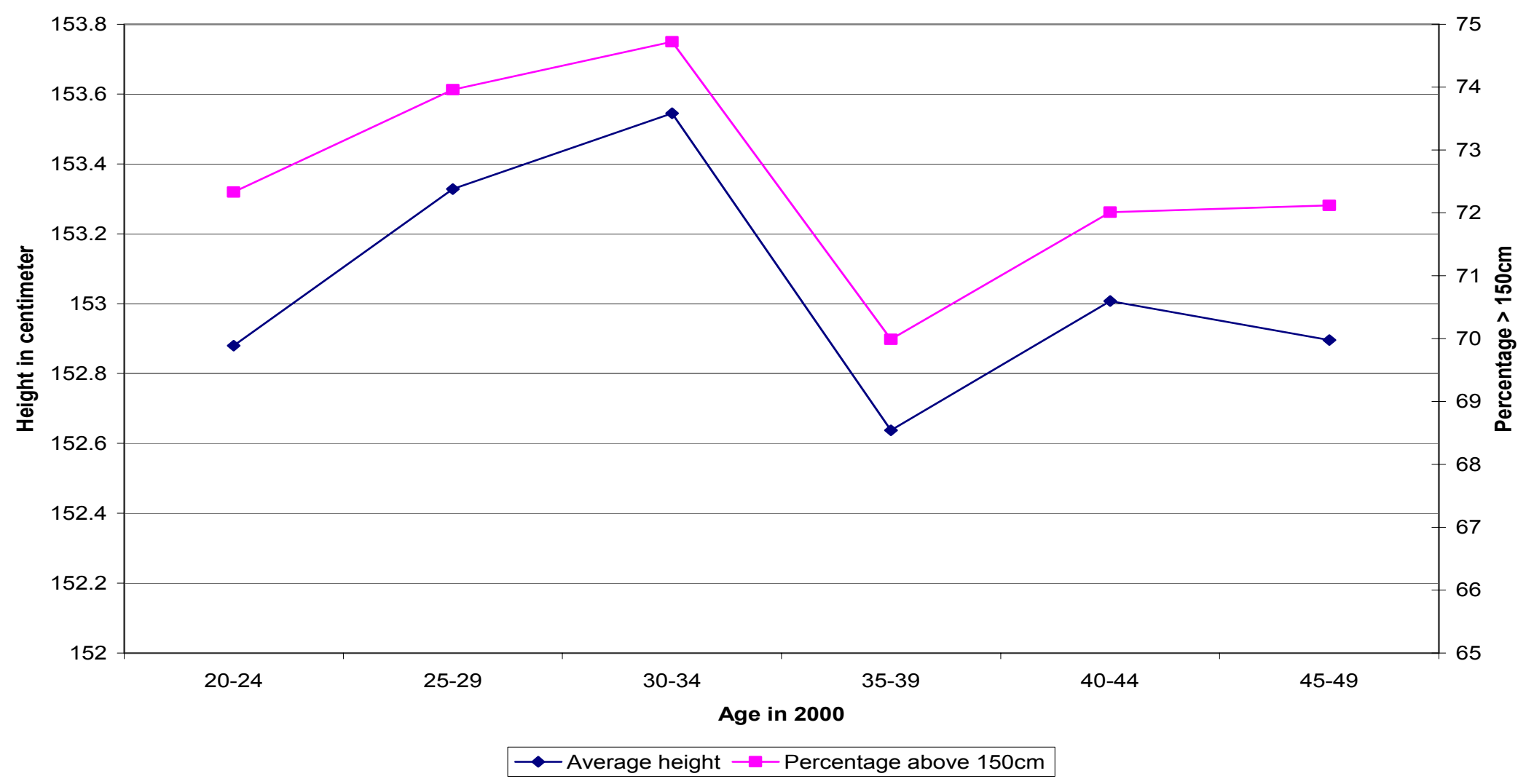


Figure 13: Disability rate by gender and age and cause of disability.

Cambodia Demographic and Health Survey 2000

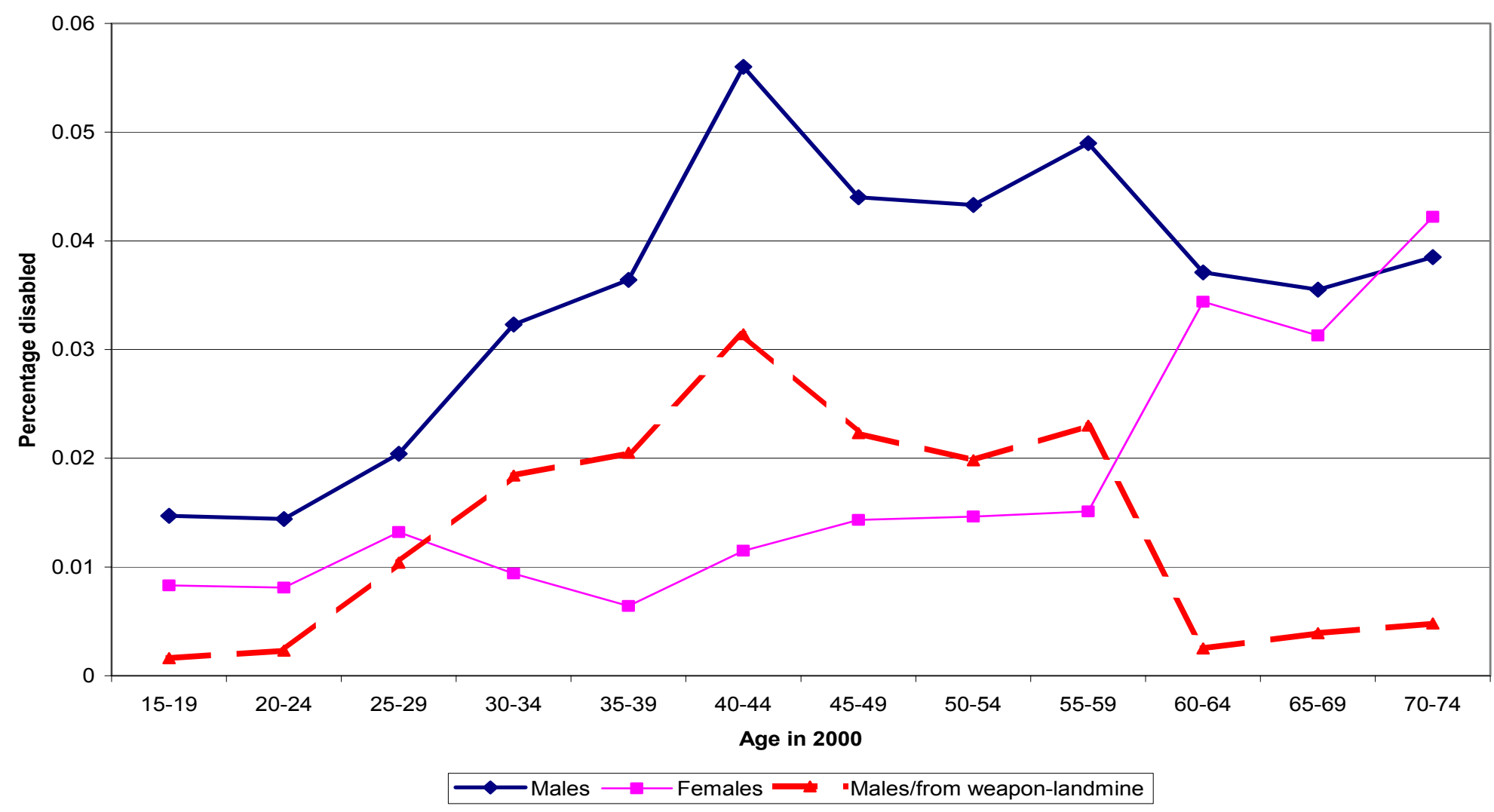


Figure 14: Average years of education by gender and age.

Cambodia Labor Force Survey 2001

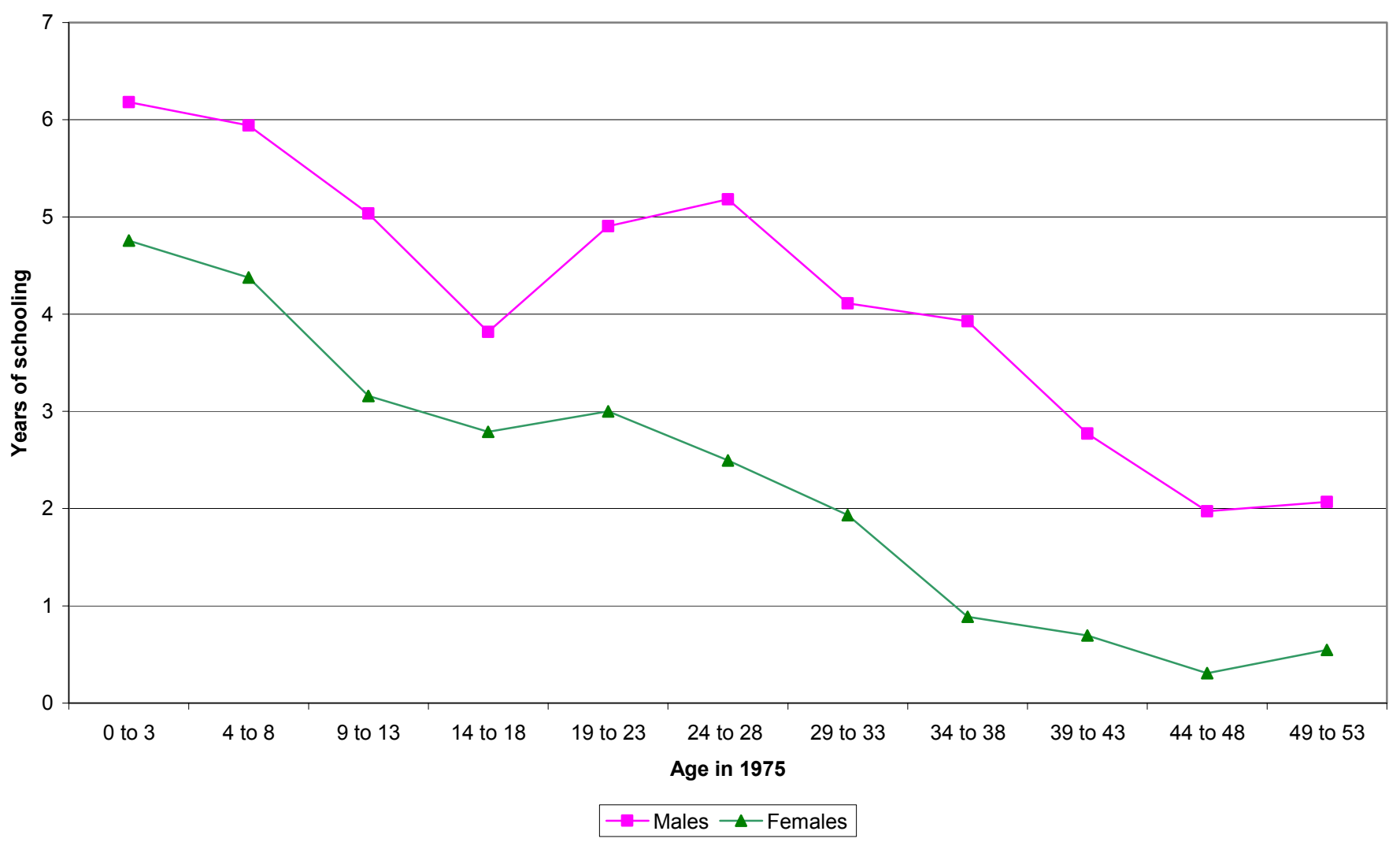


Figure 15: Percentage with at least some secondary education,

Cambodia Labor Force Survey 2001

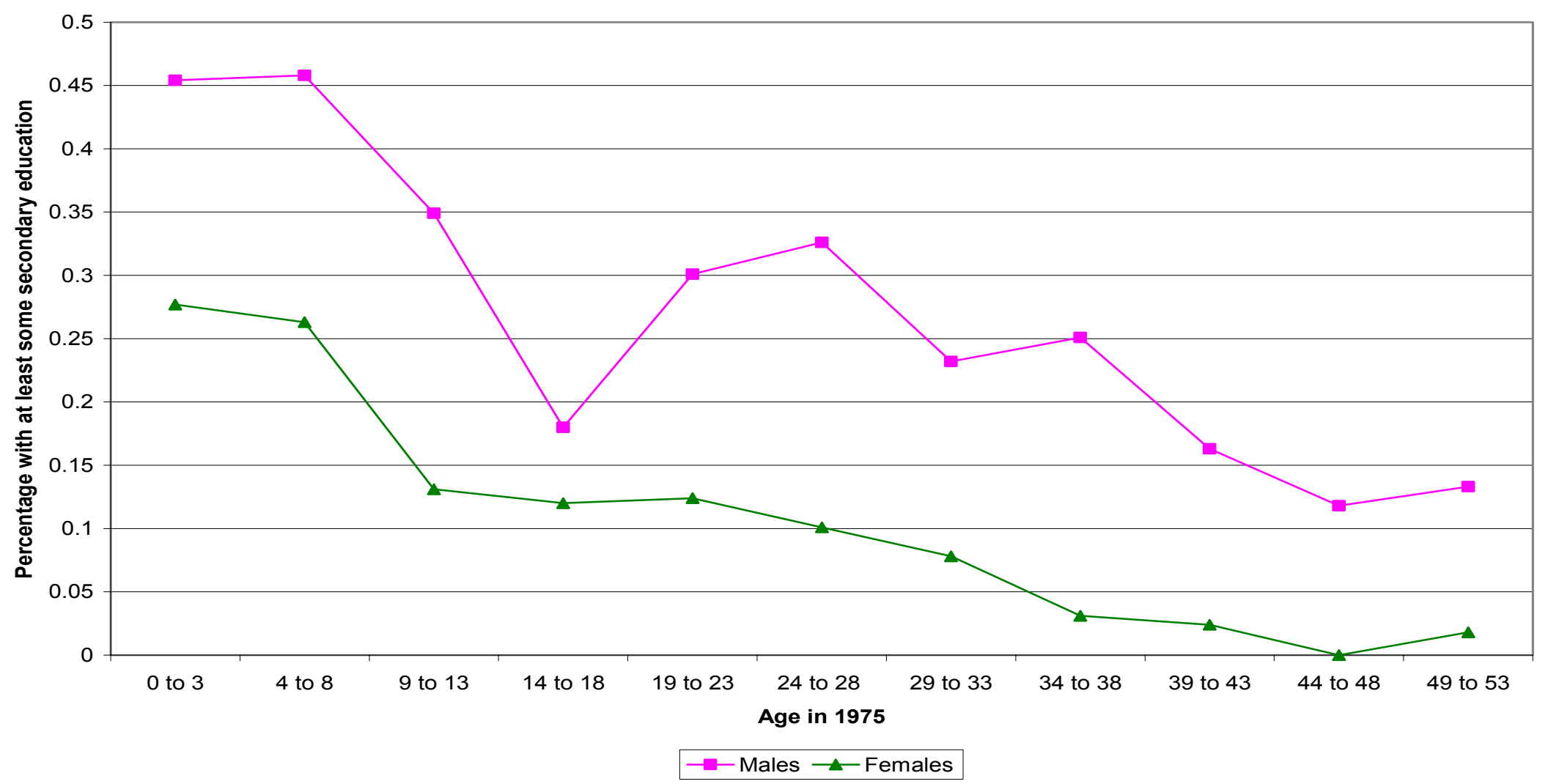


Table 1: Probability to die from five year period to five year period, by birth cohort and gender.

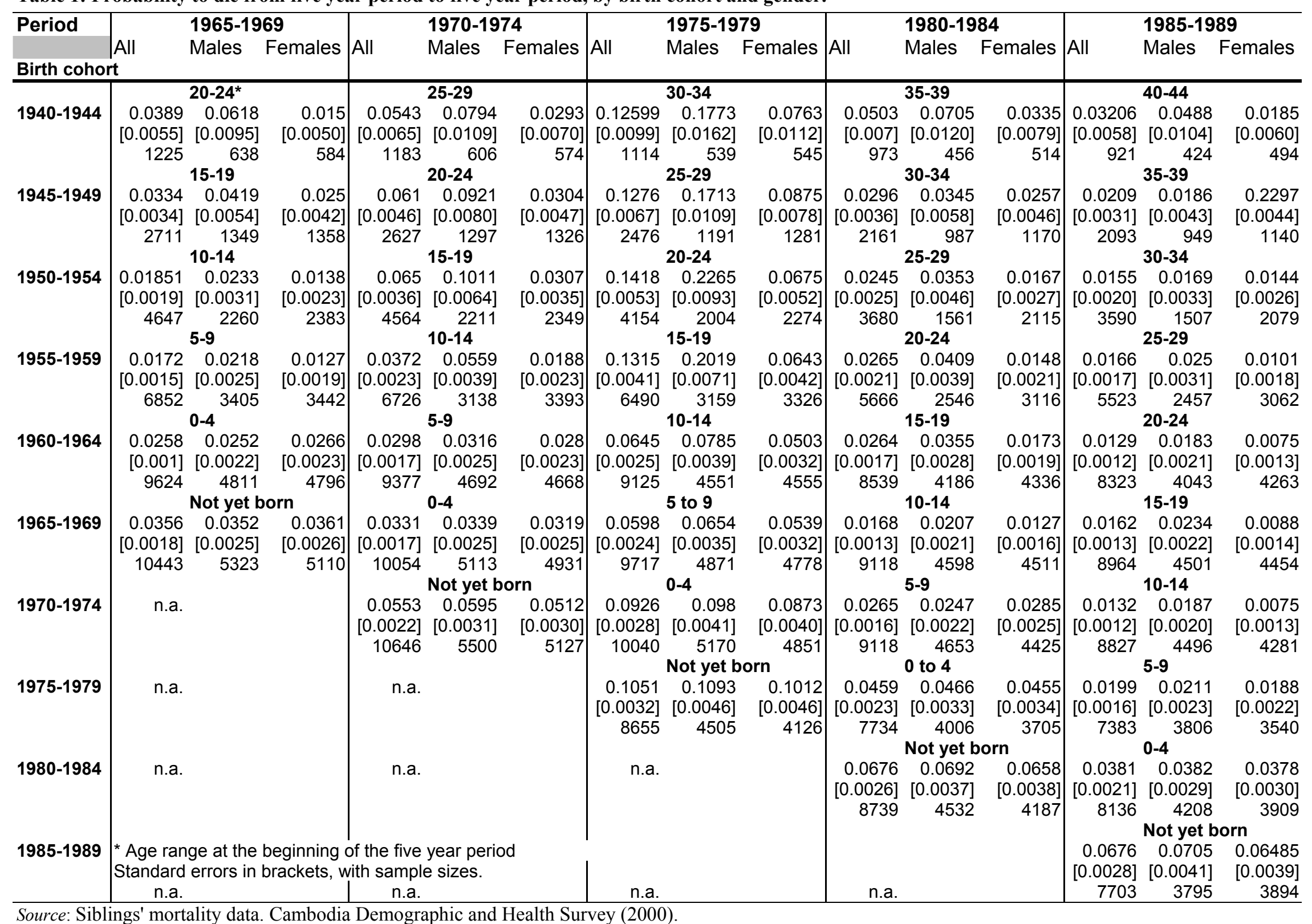


Table 2: Selective mortality (probability of death) by socio-economic status, 1975-1979

\begin{tabular}{|c|c|c|c|c|}
\hline & $\begin{array}{l}\text { Family of Rural } \\
\text { Origin }\end{array}$ & $\begin{array}{l}\text { Family of Urban } \\
\text { Origin }\end{array}$ & $\begin{array}{c}\text { Sister with } \\
\text { secondary } \\
\text { education prior to } \\
1975\end{array}$ & $\begin{array}{c}\text { Sister with less } \\
\text { than secondary } \\
\text { education prior to } \\
1975\end{array}$ \\
\hline Both genders & $\begin{array}{l}0.0889 \\
{[0.0015]} \\
N=33677\end{array}$ & $\begin{array}{l}0.1472 \\
{[0.0044]} \\
N=6416\end{array}$ & $\begin{array}{l}0.1644 \\
{[0.0120]} \\
N=954\end{array}$ & $\begin{array}{l}0.1068 \\
{[0.0028]} \\
N=12085\end{array}$ \\
\hline Males & $\begin{array}{l}0.1169 \\
{[0.0024]} \\
N=16725\end{array}$ & $\begin{array}{l}0.1848 \\
{[0.0068]} \\
N=3196\end{array}$ & $\begin{array}{l}0.2551 \\
{[0.0204]} \\
N=457\end{array}$ & $\begin{array}{l}0.1472 \\
{[0.0045]} \\
N=5957\end{array}$ \\
\hline Females & $\begin{array}{l}0.0612 \\
{[0.0018]} \\
N=16906\end{array}$ & $\begin{array}{l}0.1104 \\
{[0.0055]} \\
N=3204\end{array}$ & $\begin{array}{l}0.07951 \\
{[0.0121]} \\
N=494\end{array}$ & $\begin{array}{l}0.0677 \\
{[0.0032]} \\
N=6109\end{array}$ \\
\hline $\begin{array}{l}\text { Family of Rural } \\
\text { Origin }\end{array}$ & n.a. & n.a. & $\begin{array}{l}0.1221 \\
{[0.0145]} \\
N=507\end{array}$ & $\begin{array}{l}0.1018 \\
{[0.0029]} \\
N=10282\end{array}$ \\
\hline $\begin{array}{l}\text { Family of Urban } \\
\text { Origin }\end{array}$ & n.a. & n.a. & $\begin{array}{l}0.2232 \\
{[0.0200]} \\
N=434\end{array}$ & $\begin{array}{l}0.1450 \\
{[0.0086]} \\
N=1671\end{array}$ \\
\hline
\end{tabular}

[standard error in brackets]

Source: Cambodia DHS (2000). 
Table 3: Infant and child mortality by birth cohort, location and education of the mother

\begin{tabular}{|c|c|c|c|c|c|c|}
\hline & $\begin{array}{r}\text { Survived first } \\
\text { year } \\
\text { Birth cohort }\end{array}$ & $\begin{array}{r}\text { Survived first } \\
\text { year } \\
\text { Urban }\end{array}$ & $\begin{array}{r}\text { Survived first } \\
\text { year } \\
\text { Rural }\end{array}$ & $\begin{array}{r}\text { Survived first } \\
\text { year } \\
\text { Mother } \\
\text { Secondary }\end{array}$ & $\begin{array}{l}\text { Survived first year } \\
\text { Mother < secondary }\end{array}$ & $\begin{array}{r}\text { Survived first } 5 \\
\text { years }\end{array}$ \\
\hline \multirow[t]{3}{*}{$70-74$} & 0.871 & 0.867 & 0.872 & 0.8557 & 0.8724 & 0.7865 \\
\hline & [0.0091] & {$[0.0231]$} & [0.0099] & {$[0.0414]$} & [0.0093] & [0.0112] \\
\hline & 1334 & 216 & 1118 & 73 & 1261 & 1334 \\
\hline \multirow[t]{3}{*}{$75-79$} & 0.852 & 0.839 & 0.854 & 0.8874 & 0.8506 & 0.7806 \\
\hline & {$[0.0071]$} & [0.0202] & {$[0.0075]$} & [0.0269] & [0.0073] & [0.0082] \\
\hline & 2490 & 328 & 2162 & 138 & 2352 & 2490 \\
\hline \multirow[t]{3}{*}{$80-84$} & 0.902 & 0.935 & 0.896 & 0.9372 & 0.9 & 0.8669 \\
\hline & {$[0.0035]$} & [0.0078] & {$[0.0039]$} & {$[0.0130]$} & {$[0.0037]$} & [0.0041] \\
\hline & 6805 & 997 & 5808 & 344 & 6461 & 6805 \\
\hline \multirow[t]{3}{*}{$85-89$} & 0.912 & 0.944 & 0.907 & 0.9417 & 0.91 & 0.8848 \\
\hline & [0.0029] & [0.0064] & [0.0032] & [0.0108] & [0.0030] & [0.0033] \\
\hline & 9067 & 1258 & 7809 & 467 & 8600 & 9067 \\
\hline \multirow[t]{3}{*}{$90-94$} & 0.902 & 0.932 & 0.898 & 0.9278 & 0.899 & 0.8762 \\
\hline & {$[0.0027]$} & {$[0.0063]$} & {$[0.0030]$} & [0.0079] & [0.0029] & [0.0030] \\
\hline & 11714 & 1585 & 10129 & 1071 & 10643 & 11714 \\
\hline \multirow[t]{3}{*}{ 95-99 } & 0.904 & 0.9117 & 0.903 & 0.9466 & 0.898 & 0.8921 \\
\hline & {$[0.0031]$} & {$[0.0081]$} & {$[0.0033]$} & {$[0.0070]$} & {$[0.0034]$} & [0.0033] \\
\hline & 8760 & 1224 & 7536 & 1007 & 7753 & 8760 \\
\hline
\end{tabular}

Standard errors in brackets, with sample sizes.

Source: From birth histories, Cambodia Demographic and Health Survey (2000). 
Table 4: Age and schooling differences between partners by birth cohort of the wife. Cambodia, Demographic and Health Survey, 2000.

\begin{tabular}{|c|c|c|c|c|c|}
\hline Birth Cohort & $\begin{array}{c}\text { Age in } \\
1979 \text { (December) }\end{array}$ & Cohort size & $\begin{array}{l}\text { Mean age difference } \\
\text { with partner }\end{array}$ & $\begin{array}{l}\text { Percentage with } \\
\text { younger partner }\end{array}$ & $\begin{array}{l}\text { Mean Schooling di } \\
\text { with partne }\end{array}$ \\
\hline $50-54$ & $29-25$ & 1119 & $\begin{array}{c}3.93 \\
{[0.212]}\end{array}$ & $\begin{array}{c}0.164 \\
{[0.0125]}\end{array}$ & $\begin{array}{c}2.212 \\
{[0.092]}\end{array}$ \\
\hline $55-59$ & $24-20$ & 1619 & $\begin{array}{l}3.219 \\
{[0.17]}\end{array}$ & $\begin{array}{c}0.222 \\
{[0.011]}\end{array}$ & $\begin{array}{c}1.736 \\
{[0.075]}\end{array}$ \\
\hline $60-64$ & $19-15$ & 2049 & $\begin{array}{c}2.31 \\
{[0.126]}\end{array}$ & $\begin{array}{c}0.243 \\
{[0.0100]}\end{array}$ & $\begin{array}{c}1.768 \\
{[0.063]}\end{array}$ \\
\hline $65-69$ & $14-10$ & 1994 & $\begin{array}{c}2.137 \\
{[0.1]}\end{array}$ & $\begin{array}{c}0.234 \\
{[0.0099]}\end{array}$ & $\begin{array}{c}1.516 \\
{[0.070]}\end{array}$ \\
\hline $70-74$ & 9 to 5 & 1899 & $\begin{array}{l}2.91 \\
{[0.1]}\end{array}$ & $\begin{array}{c}0.1525 \\
{[0.0085]}\end{array}$ & $\begin{array}{c}1.49 \\
{[0.070]}\end{array}$ \\
\hline $75-79$ & 4 to 0 & 1151 & $\begin{array}{c}4.191 \\
{[0.127]}\end{array}$ & $\begin{array}{c}0.0911 \\
{[0.0087]}\end{array}$ & $\begin{array}{c}1.75 \\
{[0.100]}\end{array}$ \\
\hline
\end{tabular}

Standard deviation in brackets. 
Table 5: Height by birth cohort, women age 15-49.

\begin{tabular}{|c|c|c|c|}
\hline Age in 2000 & Age in 1975 & Average height & $\%<150 \mathrm{~cm}$ \\
\hline $15-19$ & & $\begin{array}{r}152.125 \\
{[0.130]} \\
1685\end{array}$ & $\begin{array}{r}33.45 \\
{[0.0114]} \\
1685\end{array}$ \\
\hline $20-24$ & & $\begin{array}{r}152.88 \\
{[0.1593]} \\
951\end{array}$ & $\begin{array}{r}27.67 \\
{[0.0145]} \\
951\end{array}$ \\
\hline $25-29$ & $0-4$ & $\begin{array}{r}153.328 \\
{[0.1526]} \\
1040\end{array}$ & $\begin{array}{r}26.04 \\
{[0.0136]} \\
1040\end{array}$ \\
\hline $30-34$ & 5 to 9 & $\begin{array}{r}153.545 \\
{[0.1586]} \\
1137\end{array}$ & $\begin{array}{r}25.28 \\
{[0.0128]} \\
1137\end{array}$ \\
\hline $35-39$ & 10 to 14 & $\begin{array}{r}152.638 \\
{[0.1587]} \\
1040\end{array}$ & $\begin{array}{r}30.01 \\
{[0.0138]} \\
1040\end{array}$ \\
\hline $40-44$ & 15 to 19 & $\begin{array}{r}153.008 \\
{[0.1743]} \\
890\end{array}$ & $\begin{array}{r}27.99 \\
{[0.0150]} \\
890\end{array}$ \\
\hline $\begin{array}{r}45-49 \\
\text { Total }\end{array}$ & $20-24$ & $\begin{array}{r}152.896 \\
{[0.2030]} \\
681\end{array}$ & $\begin{array}{r}27.88 \\
{[0.0171]} \\
681\end{array}$ \\
\hline
\end{tabular}

Standard errors in brackets, with sample sizes.

Source: Cambodia, Demographic and Health Survey (2000). 
Table 6: Disability and illness, by age and gender

\begin{tabular}{|c|c|c|c|c|c|c|c|c|c|c|c|c|c|}
\hline \multicolumn{2}{|c|}{ Age in 2000} & $15-19$ & $20-24$ & $25-29$ & $30-34$ & $35-39$ & $40-44$ & $45-49$ & $50-54$ & $55-59$ & $60-64$ & $65-69$ & 70-74 \\
\hline \multicolumn{14}{|c|}{ Disability } \\
\hline \multirow{6}{*}{ Males } & Mean & 0.0147 & 0.0144 & 0.0204 & 0.0323 & 0.0364 & 0.056 & 0.044 & 0.0433 & 0.04899 & 0.0371 & 0.0355 & 0.0385 \\
\hline & St. error & [0.0018] & [0.0026] & {$[0.0031]$} & [0.0038] & {$[0.0041]$} & [0.0063] & [0.0063] & [0.0069] & [0.0083] & [0.0081] & {$[0.0089]$} & [0.0117] \\
\hline & $\mathrm{N}$ & 4082 & 2075 & 1980 & 2133 & 2036 & 1328 & 1044 & 868 & 669 & 543 & 432 & 271 \\
\hline & Mean & 0.0083 & 0.0081 & 0.0132 & 0.0094 & 0.0064 & 0.01148 & 0.01432 & 0.01464 & 0.0151 & 0.0344 & 0.0313 & 0.0422 \\
\hline & St. error & [0.0014] & [0.0019] & {$[0.0024]$} & {$[0.0020]$} & {$[0.0016]$} & [0.0024] & {$[0.0030]$} & [0.0036] & [0.0041] & [0.0068] & {$[0.0073]$} & [0.0109] \\
\hline & $\mathrm{N}$ & 3700 & 2118 & 2193 & 2289 & 2244 & 1908 & 1524 & 1109 & 858 & 713 & 568 & 336 \\
\hline \multicolumn{14}{|c|}{ Illness or in jury during last 30 days } \\
\hline \multirow{3}{*}{ Males } & Mean & 0.0336 & 0.0385 & 0.0397 & 0.0443 & 0.051 & 0.052 & 0.0653 & 0.0665 & 0.0899 & 0.06485 & 0.1275 & 0.1422 \\
\hline & St. error & [0.0028] & [0.0042] & [0.0043] & [0.0044] & [0.0048] & [0.006] & {$[0.0076]$} & [0.0084] & [0.0110] & [0.0105] & {$[0.0160]$} & [0.0212] \\
\hline & $\mathrm{N}$ & 4082 & 2075 & 1980 & 2133 & 2036 & 1328 & 1044 & 868 & 669 & 543 & 432 & 271 \\
\hline \multirow[t]{3}{*}{ Females } & Mean & 0.0138 & 0.019 & 0.0237 & 0.0259 & 0.0174 & 0.0188 & 0.0354 & 0.0313 & 0.0291 & 0.0531 & 0.0452 & 0.0514 \\
\hline & St. error & [0.003] & [0.0051] & [0.0049] & [0.0057] & [0.0061] & [0.0074] & [0.0090] & [0.0101] & [0.0118] & [0.0153] & [0.0213] & [0.0268] \\
\hline & $\mathrm{N}$ & 3700 & 2118 & 2193 & 2289 & 2244 & 1908 & 1524 & 1109 & 858 & 713 & 568 & 336 \\
\hline \multicolumn{14}{|c|}{ Disability from landmine or weapon } \\
\hline \multirow[t]{3}{*}{ Males } & Mean & 0.0016 & 0.0023 & 0.0104 & 0.0184 & 0.0205 & 0.0314 & 0.0223 & 0.0198 & 0.023 & 0.0025 & 0.0039 & 0.0048 \\
\hline & St. error & [0.0006] & [0.0010] & {$[0.0022]$} & [0.0029] & {$[0.0031]$} & [0.0047] & [0.0045] & [0.0047] & [0.0058] & [0.0021] & [0.003] & {$[0.0042]$} \\
\hline & $\mathrm{N}$ & 4082 & 2075 & 1980 & 2133 & 2036 & 1328 & 1044 & 868 & 669 & 543 & 432 & 271 \\
\hline
\end{tabular}

Source: Cambodia, Demographic and Health Survey (2000). 
Table 7: Cambodia, Reconstruction of the school system

\begin{tabular}{lccc}
\hline Number of teachers & $1979-80$ & $1980-81$ & $1981-82$ \\
\hline $\begin{array}{l}\text { Level 1 } \\
\text { (4 grades) }\end{array}$ & 21,605 & 30,316 & 37,000 \\
$\begin{array}{l}\text { Level 2 } \\
\text { (3 grades) }\end{array}$ & 206 & 671 & 1600 \\
$\begin{array}{l}\text { Level 3 } \\
\text { (3 grades) } \\
\text { Source: Adapted from Kiljunen (1984). }\end{array}$ & 20 & 28 & 78 \\
\end{tabular}


Table A1:

Estimating the death toll and measuring the downward bias in using the sample based approach, by comparing it to the reconstruction approach Sources: Siblings' mortality data. Cambodia Demographic and Health Survey, 2000 and Heuveline 2001(b)

\begin{tabular}{|c|c|c|c|c|c|c|c|c|}
\hline $\begin{array}{l}\text { Population size } \\
\text { in } 1970\end{array}$ & $\begin{array}{l}\text { Death probabilities } \\
1970-1974\end{array}$ & $\begin{array}{l}\text { Deaths } \\
1970-1974\end{array}$ & $\begin{array}{l}\text { Remaining alive } \\
\text { in } 1975\end{array}$ & $\begin{array}{l}\text { Death probabilities } \\
1975-1979\end{array}$ & $\begin{array}{l}\text { Deaths } \\
1975-1979\end{array}$ & $\begin{array}{l}\text { Deaths } \\
1970-1979\end{array}$ & $\begin{array}{l}\text { Excess deaths } \\
1970-1980\end{array}$ & $\begin{array}{l}\text { Ratio sample } \\
\text { vs. reconstruction }\end{array}$ \\
\hline uveline & From Table 1 & $(2)^{\star}(4)$ & (2)-(6) & From Table 1 & $(8)^{*}(10)$ & $(5)+(11) \quad(6)+(12)$ & From Heuveline & (13)/(15) \\
\hline
\end{tabular}

\begin{tabular}{|c|c|c|c|c|c|c|c|c|c|c|c|c|c|c|c|c|c|c|}
\hline \multirow{2}{*}{$\begin{array}{l}\text { Cohort } \\
\text { born in }\end{array}$} & \multirow{2}{*}{$\begin{array}{r}\text { Males } \\
1\end{array}$} & \multirow{2}{*}{$\begin{array}{r}\text { Females } \\
2\end{array}$} & \multirow{2}{*}{$\begin{array}{r}\text { Males } \\
3\end{array}$} & \multirow{2}{*}{$\begin{array}{r}\text { Females } \\
4\end{array}$} & \multirow{2}{*}{$\begin{array}{r}\text { Males } \\
5\end{array}$} & \multirow{2}{*}{$\begin{array}{r}\text { Females } \\
6 \\
\end{array}$} & \multirow{2}{*}{$\begin{array}{r}\text { Males } \\
7\end{array}$} & \multirow{2}{*}{$\begin{array}{r}\text { Females } \\
8\end{array}$} & \multirow{2}{*}{$\begin{array}{r}\text { Males } \\
9\end{array}$} & \multirow{2}{*}{$\begin{array}{r}\text { Females } \\
10\end{array}$} & \multirow{2}{*}{$\begin{array}{r}\text { Males } \\
11\end{array}$} & \multirow{2}{*}{$\begin{array}{r}\text { Females } \\
12\end{array}$} & \multirow{2}{*}{$\begin{array}{r}\text { Males } \\
13\end{array}$} & \multirow{2}{*}{$\begin{array}{r}\text { Females } \\
14\end{array}$} & \multirow{2}{*}{$\begin{array}{r}\text { Males } \\
15\end{array}$} & \multirow{2}{*}{$\begin{array}{r}\text { Females } \\
16\end{array}$} & \multirow{2}{*}{$\begin{array}{r}\text { Males } \\
17\end{array}$} & \multirow{2}{*}{$\begin{array}{r}\text { Females } \\
18\end{array}$} \\
\hline & & & & & & & & & & & & & & & & & & \\
\hline & & & $25-29^{*}$ & & & & & & $30-34$ & & & & & & & & & \\
\hline \multirow[t]{2}{*}{$1940-44$} & 244900 & 249800 & 0.08 & 0.03 & 19445 & 7319 & 225455 & 242481 & 0.18 & 0.08 & 39973 & 18501 & 59418 & 25820 & 95900 & 47700 & 0.62 & 0.54 \\
\hline & & & $20-24$ & & & & & & $25-29$ & & & & & & & & & \\
\hline \multirow[t]{2}{*}{$1945-49$} & 313500 & 311800 & 0.09 & 0.03 & 28873 & 9479 & 284627 & 302321 & 0.17 & 0.09 & 48757 & 26453 & 77630 & 35932 & 134600 & 60300 & 0.58 & 0.60 \\
\hline & & & $15-19$ & & & & & & $20-24$ & & & & & & & & & \\
\hline \multirow[t]{2}{*}{$1950-54$} & 411800 & 404600 & 0.10 & 0.03 & 41633 & 12421 & 370167 & 392179 & 0.23 & 0.07 & 83843 & 26472 & 125476 & 38893 & 191800 & 92100 & 0.65 & 0.42 \\
\hline & & & 10 to 14 & & & & & & $15-19$ & & & & & & & & & \\
\hline \multirow[t]{2}{*}{ 1955-59 } & 490200 & 479200 & 0.06 & 0.02 & 27402 & 9009 & 462798 & 470191 & 0.20 & 0.06 & 93439 & 30233 & 120841 & 39242 & 220400 & 110600 & 0.55 & 0.35 \\
\hline & & & 5 to 9 & & & & & & 10 to 14 & & & & & & & & & \\
\hline \multirow[t]{2}{*}{$1960-64$} & 582000 & 564000 & 0.03 & 0.03 & 18391 & 15792 & 563609 & 548208 & 0.08 & 0.05 & 44243 & 27575 & 62634 & 43367 & 224300 & 134700 & 0.28 & 0.32 \\
\hline & & & 0 to 4 & & & & & & 5 to 9 & & & & & & & & & \\
\hline 1965-69 & 715700 & 691200 & 0.03 & 0.03 & 24262 & 22049 & 691438 & 669151 & 0.07 & 0.05 & 45220 & 36067 & 69482 & 58117 & 229600 & 180500 & 0.30 & 0.32 \\
\hline \multicolumn{19}{|l|}{ Total } \\
\hline $\begin{array}{l}\text { Born } \\
1940-69\end{array}$ & 2758100 & 2700600 & & & 160007 & 76069 & 2598093 & 2624531 & & & 355475 & 165302 & 515482 & 241371 & 1096600 & 625900 & 0.47 & 0.39 \\
\hline
\end{tabular}

${ }^{*}$ Age range at the beginning of the five year period

Data for the baseline population in 1970 and for the excess deaths between 1970-80 are taken from Table 5-1, p. 122 of Heuveline 2001(b).

Notice: This table aims at measuring the extent of the downward bias implied by the sample approach used in this paper.

The author believes that for estimating the death toll in absolute numbers, the demographic reconstruction approach is more appropriate. This table should be read together with the appendix. 